\title{
Characterising the three-dimensional ozone distribution of a tidally locked Earth-like planet
}

Elisavet Proedrou ${ }^{1,2^{*}+}$ and Klemens Hocke $e^{1,2,3+}$

\begin{abstract}
We simulate the 3D ozone distribution of a tidally locked Earth-like exoplanet using the high-resolution, 3D chemistryclimate model CESM1 (WACCM) and study how the ozone layer of a tidally locked Earth (TLE) ( $\Omega_{\text {TLE }}=1 / 365$ days) differs from that of our present-day Earth (PDE) $\left(\Omega_{\mathrm{PDE}}=1 / 1\right.$ day). The middle atmosphere reaches a steady state asymptotically within the first 80 days of the simulation. An upwelling, centred on the subsolar point, is present on the day side while a downwelling, centred on the antisolar point, is present on the night side. In the mesosphere, we find similar global ozone distributions for the TLE and the PDE, with decreased ozone on the day side and enhanced ozone on the night side. In the lower mesosphere, a jet stream transitions into a large-scale vortex around a low-pressure system, located at low latitudes of the TLE night side. In the middle stratosphere, the concentration of odd oxygen is approximately equal to that of the ozone $\left[\left(\mathrm{O}_{x}\right) \approx\left(\mathrm{O}_{3}\right)\right]$. At these altitudes, the lifetime of odd oxygen is $\sim 16 \mathrm{~h}$ and the transport processes significantly contribute to the global distribution of stratospheric ozone. Compared to the PDE, where the strong Coriolis force acts as a mixing barrier between low and high latitudes, the transport processes of the TLE are governed by jet streams variable in the zonal and meridional directions. In the middle stratosphere of the TLE, we find high ozone values on the day side, due to the increased production of atomic oxygen on the day side, where it immediately recombines with molecular oxygen to form ozone. In contrast, the ozone is depleted on the night side, due to changes in the solar radiation distribution and the presence of a downwelling. As a result of the reduced Coriolis force, the tropical and extratropical air masses are well mixed and the global temperature distribution of the TLE stratosphere has smaller horizontal gradients than the PDE. Compared to the PDE, the total ozone column global mean is reduced by $\sim 19.3 \%$. The day side and the night side total ozone column means are reduced by 23.21 and $15.52 \%$, respectively. Finally, we present the total ozone column (TOC) maps as viewed by a remote observer for four phases of the TLE during its revolution around the star. The mean TOC values of the four phases of the TLE vary by up to $23 \%$.
\end{abstract}

Keywords: Exoplanet, Tidally locked Earth, Middle atmosphere, Circulation, Ozone layer, Photochemistry, Total ozone, Daytime, Day side, Night side

\section{Introduction}

In this study, we simulate and analyse the middle atmospheric ozone distribution of a tidally locked Earth-like exoplanet orbiting a Sun-like star (TLE) using a realistic, high-resolution, 3D chemistry-climate model. We aim to investigate the evolution of the planet's ozone

\footnotetext{
*Correspondence: elisavet.proedrou@iap.unibe.ch

${ }^{\dagger}$ Elisavet Proedrou and Klemens Hocke contributed equally to this work

${ }^{1}$ Institute of Applied Physics, University of Bern, Sidlerstrasse 5, 3012 Bern, Switzerland

Full list of author information is available at the end of the article
}

layer towards a steady state, determine its main characteristics and compare them to those of the present-day Earth (PDE). This comparative study aims to improve our understanding of the role of photochemistry and transport processes in the middle atmosphere of exoplanets. We are also interested in the planet's total ozone column (TOC) and its day side-night side variation. In the case of the present-day Earth, the day-night variation of the TOC is less than $2 \%$.

An exoplanet's ozone layer can be observed through the absorption band in the $9.6 \mu \mathrm{m}$ region of the spectrum. 
The importance of the existence of an ozone layer lies in its ability to protect life on the surface of the planet from the harmful stellar UV radiation. It has been determined that for the generation of a protective ozone layer only a small amount of oxygen ( 0.1 of the present atmospheric levels) is sufficient (Kasting and Donahue 1980).

Yang et al. (2014) studied the dependence of a planet's habitability on its rotation rate using two 3D models, the CAM3 and the CCSM3. CAM3 is a 3D GCM standalone atmospheric circulation model, which calculates the atmospheric circulation and radiative transfer, as well as the small-scale vertical convection, clouds and precipitation. CCSM3 is a 3D GCM coupled ocean-atmosphere model. Its ocean component calculates the oceanic circulation using an ocean with uniform depth and albedo and no circulation. The CCSM3's atmospheric components are the CAM3 or the CAM4. They are able to simulate the marine stratus, layered, shallow convective and deep convective clouds as well as liquid and ice condensates. CAM4 has a cloud scheme similar to that of the CAM3 and an improved deep convection scheme. Both models are precursors of the model used in our paper. The study of Yang et al. (2014) focused on the troposphere of the simulated planets. They demonstrated that a slow rotating Earth-like planet (rotation speed $=1$ rotation $/ 243$ days), located at a distance of 0.7 AU away from a Sun-like star, would be habitable. They also determined that an Earth-like planet rotating at a rate of 1 rotation/day required half the stellar flux compared to an Earth-like planet rotating at a rate of 1 rotation/243 days to maintain an Earth-like climate.

The planets orbiting $\mathrm{M}$ stars are prime targets in the search for terrestrial habitable exoplanets (Tarter et al. 2007). M stars comprise $76 \%$ of the stars in the Sun's neighbourhood. Owing to the good mass and radius star-planet ratio, such planets have a high probability of being detected.

Habitability studies performed for such tidally locked exoplanets by Haberle et al. (1996), Joshi et al. (1997) and Joshi (2003) have shown that terrestrial planets located in an M star's habitable zone (0.02-0.2 AU) (Tarter et al. 2007) would be habitable as long as liquid water and the chemical constituents necessary for the emergence of life were present on them for a sufficiently long period of time. Furthermore, Segura et al. (2010) concluded that the flares emitted by $M$ stars should not pose a threat to the surface life of an orbiting habitable planet.

$M$ stars have a weaker UV and visible emission than the Sun, with the spectrum peaking in the infrared. The impact of different stellar spectral energy distributions on the ozone distribution of habitable non-tidally locked terrestrial extrasolar planets has been studied by Selsis (2000), Segura et al. (2003, 2005), Grenfell et al. (2007),
Rugheimer et al. (2013), Rauer et al. (2011) and Godolt et al. (2015).

Selsis (2000) used a 1D atmospheric model to simulate how the chemical and thermal structure of the Earth would have evolved, had it been orbiting a F9 and a K2 star. His simulations revealed that the amount of ozone increased with increases in the UV/visible ratio. F9 stars have a higher UV/visible ratio than the Sun, whereas K2 stars have a lower UV/visible ratio. The study also showed that the thickness of the ozone layer increased with the strength of the UV flux, resulting in higher amounts of ozone for the planet orbiting the F9 star and lower amounts for the planet orbiting the K2 star, compared to the Earth. Despite the decreased amounts of ozone, the planet orbiting the $\mathrm{K} 2$ star would have a visible $\mathrm{O}_{3}$ spectral signature as a result of the temperature contrast between the surface and the atmosphere. However, the planet orbiting the F9 star would have no distinguishable ozone spectral signature, despite the planet's higher atmospheric ozone levels.

Segura et al. used a 1D coupled radiative-convective photochemical model to calculate the spectra of Earthlike planets orbiting a F2V, a G2V, a K2V (Segura et al. 2003) and an M star (Segura et al. 2005), respectively. They determined that in the case of planets orbiting the F2V, G2V and K2V orbiting stars, the ozone $9.6 \mu \mathrm{m}$ spectral line should be visible if the planet's $\mathrm{O}_{2}$ concentration was at least $10^{-3}$ of the present atmospheric levels (PAL). They also determined that at $1 \mathrm{PAL} \mathrm{O}_{2}$ levels, the ozone concentration in a planet orbiting an F2V star would be weaker than around a G2V or a K2V star. This result is not consistent with that of Selsis (2000). For the case of an active $M$ star orbiting planet, Segura et al. (2005) found that a similar Earth-like ozone layer would develop, resulting in an observable $\mathrm{O}_{3} 9.6 \mu \mathrm{m}$ spectral line, comparable to that of the Earth (Segura et al. 2005).

Grenfell et al. (2007) used a 1D coupled radiativeconvective photochemical column model to calculate changes in the atmospheric composition of a planet with the Earth's atmospheric composition, when subjected to 5-10\% changes of its orbital position around a solar-type G2V star, a F2V star and a K2V star. They found that as the planets were moved outwards, the ozone increased by $\sim 10 \%$, as a result of the decreased stratospheric temperature.

Rugheimer et al. (2013) simulated the spectra of clear and cloudy Earth-like planets orbiting F, G and K stars at 1 AU equivalent distances, using a geometrical 1D global atmospheric model. They determined that an increase in either the parent star's UV radiation or its temperature resulted in increased $\mathrm{O}_{3}$ concentrations and stronger $\mathrm{O}_{3}$ spectral features. 
Rauer et al. (2011) calculated the molecular absorption bands of the atmospheres of super-Earth planets orbiting $\mathrm{M}$ stars, using a plane-parallel, 1D climate model, coupled with a chemistry model. They predicted that the ozone emission spectra observed during a secondary eclipse for planets orbiting quiet M0 to M3 dwarfs would be stronger than the PDE. On the other hand, the ozone emission spectra of planets orbiting very cool and quiet M4 to M7 stars would be weaker, as a result of increases in their mid-atmospheric temperatures.

Grenfell et al. (2013) performed a sensitivity study of the atmosphere of an Earth-like planet using a global mean radiative-convective photochemical column model. They varied the stellar class and gravity of the planet and investigated how the changes affected the resulting photochemistry and climate and hence the potential observed biosignatures. Their study revealed that for an M0 star, the stratospheric ozone generation was still dominated by the Chapman cycle, but it was somewhat suppressed (89.2\%) compared to the Sun scenario $(90.5 \%)$. The ozone generation through the smog mechanism was increased (by $9.1 \%$ ) compared to the Sun scenario (by $0.8 \%$ ). The balance between the Chapman mechanism and the smog mechanisms shifted towards the smog mechanism as one moved towards cooler stars. For cool M5-M7 stars, the stratospheric ozone photochemistry was completely smog-dominated.

Godolt et al. (2015) used a state-of-the-art 3D Earth climate model, which accounted for local and dynamical processes, to study the influence of F, G and $\mathrm{K}$ stars on the stratospheric temperature, climate and potential habitability of Earth-like extrasolar planets. The planets were positioned at certain orbital distances around the stars, such that the total amount of energy received from the parent stars would equal the solar constant. A fixed Earth-like atmosphere was used, and no atmospheric chemistry calculations were performed. The study revealed that, similar to Selsis (2000), Segura et al. (2003, 2005), Grenfell et al. (2007), Rugheimer et al. (2013) and Rauer et al. (2011), different stellar spectral energy distributions resulted in different ozone heating rates and therefore different vertical temperature structures. The stratosphere of planets orbiting K stars, which are cooler than our Sun and therefore emit a smaller portion of their radiation in the UV part of the spectrum, was characterised by lower ozone heating rates and shallower stratospheric temperature increases compared to the Earth.

The above studies demonstrated that for the same total amount of stellar energy incident at the top of the atmosphere, changes in the stellar spectral energy distribution result in changes in the ozone radiative heating rate. This leads to different stratospheric temperature structures in Earth-like exoplanets. For non-tidally locked, M star orbiting, planets, the reduced UV radiation emission could result in the development of a cooler stratosphere and changes in their stratospheric ozone concentration. It is reasonable to assume that tidally locked planets would be equally affected.

Studies of the ozone concentration of a tidally locked planet would need to account for both the effects of the tidal locking and the altered stellar irradiance spectrum. This would complicate the cause-effect attribution analysis, making the attribution of the changes in the ozone distribution to either the tidal locking or the altered UV radiation exceedingly challenging. We therefore did not include the effects of the altered UV radiation in our study and focused only on the magnitude of the impact of tidal locking on the Earth-like planet orbiting a Sun-like star.

Past studies on the atmospheres of tidally locked Earthlike exoplanets were focused on the troposphere. Merlis and Schneider (2010) used an ideal gas GCM with an active hydrological cycle, a grey radiation scheme and a slab ocean lower boundary condition to simulate the troposphere of an Earth-like, tidally locked aquaplanet with a rotation period equal to one Earth year. Their study revealed that while the subsolar point surface temperature was $\sim 300 \mathrm{~K}$, the antisolar point temperature was much lower but never dropped below $240 \mathrm{~K}$, and therefore, no atmospheric collapse occurred on the night side. Furthermore, they reported the presence of a strong upwelling above the subsolar point on the day side, due to radiative heating. On the night side, they reported the presence of a downwelling, generated by radiative cooling, centred over the antisolar point.

Yang et al. (2013) showed that the presence of clouds in the troposphere of a tidally locked aquaplanet, especially over the subsolar point, can ensure habitability at almost twice the solar flux on Earth.

Grenfell et al. (2014) used a global mean, stationary, hydrostatic, atmospheric column model to perform a 1D simulation of an Earth-like exoplanet atmosphere. The model atmosphere extended from the surface to 70 $\mathrm{km}$ and had the starting composition, pressure and temperature of the 1976 US Standard Atmosphere. In the simulation, the UV emission of a cool M7 star was varied, and the resulting climate-photochemical response of the planetary atmosphere including numerous, catalytic processes of $\mathrm{O}_{3}$ depletion was calculated. The study showed that the strongest $\mathrm{O}_{3}$ emission is generated at ten times the stellar UV radiative flux of an M7 star and that an exoplanet's $\mathrm{O}_{3} 9.6 \mu \mathrm{m}$ spectral line profile is strongly influenced by the $200 \mathrm{~nm}$ and $350 \mathrm{~nm}$ UV output of the parent star.

A fundamental parameter for the description and the observation of the planetary ozone layer is the total 
ozone column (TOC). Currently the Earth's TOC is measured by several satellite missions such as Aura/OMI (Veefkind et al. 2006) and Metop/GOME-2 (Callies et al. 2004) providing global maps of TOC with a horizontal resolution of $80 \times 40 \mathrm{~km}$. The $\mathrm{O}_{3}$ distribution is determined primarily by the Brewer-Dobson circulation and the photochemistry (Brasseur and Solomon 2005).

Below, we first describe the model used for our simulations and the simulation setup. Next, we present the partial ozone content (POC) and TOC of the planet. Lastly, we present four different phases of the planet's TOC as viewed by an observer.

\section{Model description}

The Community Earth System Model (CESM) version 1.04 is used to perform our simulation. It consists of five fully coupled geophysical models: atmosphere (ATM), land (LND), ocean (OCN), sea-ice (ICE) and land-ice (GLC). The models can be set as fully prognostic, data or stub and are "state-of-the-art climate prediction and analysis tools" (Vertenstein et al. 2012) when set in the prognostic mode.

The surface parameter fluxes are provided by the land (LND), ocean (OCN), surface ice (GLC) and sea-ice (ICE) models. They provide the lower flux boundary conditions for the turbulent mixing, the planetary boundary layer parametrisation, the vertical diffusion and the gravity wave drag. In our simulation, the OCN, GLC and ICE use prescribed data, while the LND is an active model [Community Land Model (CLM)]. CLM calculates among other parameters, the absorption, reflection and transmittance of solar radiation, the absorption and emission of longwave radiation, the surface colour variability, the surface albedo, the sensible heat, the latent land surface heat fluxes, the heat transfer in soil and snow and the atmosphere-surface coupling (Neale et al. 2012).

The atmospheric model used in our simulation is the Whole Atmosphere Community Climate Model version 4 [CESM1(WACCM)] (Neale et al. 2012). CESM1(WACCM) has been used to simulate the circulation, gravity waves and atmospheric composition changes due to the chemistry and photochemistry in the lower, middle and upper atmosphere (Pedatella et al. 2014; Pedatella and Liu 2013; Lu et al. 2012; Tan et al. 2012a, b, c; Davis et al. 2013; Smith et al. 2012). Furthermore, it is fully coupled to the land and ocean models (Vertenstein et al. 2012).

It has 66 vertical levels from the ground up to $5 \times 10^{-6}$ $\mathrm{hPa}(150 \mathrm{~km})$ and is purely isobaric above $100 \mathrm{hPa}$. It has a vertical resolution of $1.1 \mathrm{~km}$ in the troposphere, 1.1-1.4 $\mathrm{km}$ in the lower stratosphere, $1.75 \mathrm{~km}$ at the stratopause and $3.5 \mathrm{~km}$ above $65 \mathrm{~km}$ altitude. The coupler timestep is $\Delta t=30 \mathrm{~min}$, while the timestep for the dynamics equations is $\Delta \tau=\Delta t / 8$ (Neale et al. 2012). It has a composition identical to that of the present-day Earth on 21.03.2000 (Neale et al. 2012).

CESM1(WACCM) has full tropospheric and stratospheric chemistry as well as mesospheric chemistry, with 57 chemistry species (Neale et al. 2012). The gasphase chemistry is coupled to the Modal Aerosol Model (Neale et al. 2012). The stratospheric distributions of long-lived species are taken from previously performed CESM1(WACCM) simulations (Neale et al. 2012). The main physical processes included in the model are:

- conversion to and from dry and wet mixing ratios for trace constituents

- moist turbulence

- shallow and the deep convection

- evaporation of convective precipitation

- cloud microphysics and macrophysics

- aerosol processes

- condensed phase optics

- radiative transfer

- surface exchange formulations

- dry adiabatic adjustment

- prognostic greenhouse gases (Neale et al. 2012).

The radiative transfer calculations in the longwave and shortwave are provided by the radiation code RRTMG (Iacono et al. 2008; Mlawer et al. 1997), which is an accelerated and modified version of the correlated k-distribution model RRTM. It efficiently calculates the irradiance and heating rates in broad spectral intervals, while retaining a high level of accuracy relative to measurements and high-resolution line-by-line models. It also distinguishes between the direct and scattered solar radiation.

The radiative transfer is calculated over 14 bands in the shortwave spectrum $(0.2-12.2 \mu \mathrm{m})$ and 16 bands in the longwave spectrum $(3.1-1000.0 \mu \mathrm{m})$. The 16th longwave band includes the infrared contribution from the spectral interval below $3.1 \mu \mathrm{m}$. Above $65 \mathrm{~km}$, the model also covers the spectrum interval between soft X-rays and extreme ultraviolet irradiances $(0.05 \mathrm{~nm}$ to Lyman- $\alpha$ $121.6 \mathrm{~nm}$ ) and the spectrum interval between the Lyman$\alpha$ and $100 \mu \mathrm{m}$ (Neale et al. 2012).

The total shortwave fluxes have an accuracy of 1-2 $\mathrm{W} / \mathrm{m}^{2}$ compared to the standard RRTM SW (using DISORT with 16 streams) for clear sky conditions and aerosols and an accuracy of $6 \mathrm{~W} / \mathrm{m}^{2}$ in overcast sky conditions. The total longwave fluxes have an accuracy of 1.0 $\mathrm{W} / \mathrm{m}^{2}$ at all levels. "Longwave radiative transfer is performed over a single angle for one upward and one downward calculation" (Neale et al. 2012). The absorption coefficients for the k-distributions of both the shortwave and the longwave radiation calculations in RRTMG are 
obtained from the line-by-line radiation model LBLRTM (Clough and Iacono 1995; Clough et al. 2005).

The calculation of the photolysis coefficients is divided into the $120-200$ and $200-750 \mathrm{~nm}$ regions. The total photolytic rate constants are calculated by the model by integrating the product of the wavelength dependent exo-atmospheric flux, the atmospheric transmission function, the molecular absorption cross section and the quantum yield for each absorbing species. The exoatmospheric flux is provided by observations and varies over the 11-year solar sunspot cycle. The transmission function is wavelength dependent and a function of the abundance of ozone and molecular oxygen in the model. For wavelengths above $200 \mathrm{~nm}$, the molecular absorption cross section and the quantum yield are calculated by the model, while below $200 \mathrm{~nm}$, their values are pre-defined. This approach works for all species except $\mathrm{NO}$ and $\mathrm{O}_{2}$ for which detailed photolysis parametrisations are included in the model. The impact of clouds on the photolysis rates is parametrised, but the impact of tropospheric and stratospheric aerosols on photolysis rates is not calculated (Neale et al. 2012).

The CESM model uses the Kurucz solar source function whose radiative transfer calculation is based upon solar measurements. It assumes a total solar irradiance at the top of the atmosphere of TSI $=1368.22 \mathrm{~W} / \mathrm{m}^{2}$. The value is then "scaled in each spectral band through the specification of a time-varying solar spectral irradiance" (Neale et al. 2012). The model uses a combination of solar parametrisations to specify the spectral irradiances over two spectral intervals (soft X-ray to Lyman- $\alpha(\lambda=121.6$ $\mathrm{nm})$ and from Lyman- $\alpha$ to $100 \mu \mathrm{m})$. The first spectral interval fluxes are calculated using the parametrisation of Solomon and Qiang (2005). It accepts as input the 10.7 $\mathrm{cm}$ solar radio flux, whose daily values are obtained from the NOAA's Space Environment Center (www.sec.noaa. gov) and its 81-day average (f 10.7a). The second spectral interval fluxes are calculated using the empirical model of the wavelength-depending sunspot and facular influences (Lean 2000; Wang et al. 2005; Neale et al. 2012).

In the shortwave, $\mathrm{H}_{2} \mathrm{O}, \mathrm{O}_{3}, \mathrm{CO}_{2}, \mathrm{O}_{2}, \mathrm{CH}_{4}, \mathrm{~N}_{2}$, clouds, aerosols and Rayleigh scattering are the modelled sources of absorption and scattering. In the longwave, $\mathrm{H}_{2} \mathrm{O}, \mathrm{CO}_{2}$, $\mathrm{O}_{3}, \mathrm{~N}_{2} \mathrm{O}, \mathrm{CH}_{4}, \mathrm{O}_{2}, \mathrm{~N}_{2}, \mathrm{CFC}-11$ and $\mathrm{CFC}-12$ are the molecular sources of absorption. The shortwave radiation is calculated only for zenith angles larger than zero (Neale et al. 2012).

The model computes the chemical equilibrium of 36 photochemical species $\left(\mathrm{O}_{2}, \mathrm{O}_{3}, \mathrm{~N}_{2} \mathrm{O}, \mathrm{NO}, \mathrm{NO}_{2}, \mathrm{~N}_{2} \mathrm{O}_{5}\right.$, $\mathrm{HNO}_{3}, \mathrm{NO}_{3}, \mathrm{HO}_{2} \mathrm{NO}_{2}, \mathrm{CH}_{3} \mathrm{OOH}, \mathrm{CH}_{2} \mathrm{O}, \mathrm{H}_{2} \mathrm{O}, \mathrm{H}_{2} \mathrm{O}_{2}$, $\mathrm{Cl}_{2}, \mathrm{ClO}, \mathrm{OClO}, \mathrm{Cl}_{2} \mathrm{O}_{2}, \mathrm{HOCl}, \mathrm{HCl}, \mathrm{ClONO}_{2}, \mathrm{BrCl}, \mathrm{BrO}$, $\mathrm{HOBr}, \mathrm{BrONO}_{2}, \mathrm{CH}_{3} \mathrm{Cl}, \mathrm{Ccl}_{4}, \mathrm{CH}_{3} \mathrm{CCl}_{3}$, CFC11, CFC12, CFC113, $\left.\mathrm{HCFC} 22, \mathrm{CH}_{3} \mathrm{Br}, \mathrm{CF}_{3} \mathrm{Br}, \mathrm{CF}_{2} \mathrm{ClBr}, \mathrm{CO}_{2}, \mathrm{CH}_{4}\right)$.
The atmospheric tracers in the model are the $\mathrm{O}_{x}, \mathrm{NO}_{x}$, $\mathrm{HO}_{x}, \mathrm{ClO}_{x}$ and $\mathrm{BrO}_{x}$ chemical families, excluding $\mathrm{O}_{2}$, along with $\mathrm{CH}_{4}$ and its degradation products. The main photochemical and chemical interactions responsible for changing the atmospheric ozone concentration are described by the reaction rate of ozone:

$$
\begin{aligned}
& \frac{d\left(\mathrm{O}_{3}\right)}{d \mathrm{t}}+J_{\mathrm{O}_{3}}\left(\mathrm{O}_{3}\right)+k_{3}(\mathrm{O})\left(\mathrm{O}_{3}\right)+a_{2}(\mathrm{H}) \\
& \left(\mathrm{O}_{3}\right)+a_{6}(\mathrm{OH})\left(\mathrm{O}_{3}\right)+a_{6 b}\left(\mathrm{HO}_{2}\right)\left(\mathrm{O}_{3}\right) \\
& \quad+b_{4}(\mathrm{NO})\left(\mathrm{O}_{3}\right)+b_{9}\left(\mathrm{NO}_{2}\right)\left(\mathrm{O}_{3}\right)+d_{2}(\mathrm{Cl})\left(\mathrm{O}_{3}\right) \\
& \quad+e_{2}(\mathrm{Br})\left(\mathrm{O}_{3}\right)=k_{2}(\mathrm{M})\left(\mathrm{O}_{2}\right)(\mathrm{O})
\end{aligned}
$$

$\frac{d\left(\mathrm{O}_{3}\right)}{d t}$ is the production rate of $\mathrm{O}_{3} \cdot \mathrm{J}_{\mathrm{O}_{3}}$ is the photolysis rate of ozone, and its values were taken from different sources depending on its molecular absorption cross section $\sigma$ and the quantum yield $(\phi)[\sigma: 136.5-175 \mathrm{~nm}$ (Tanaka et al. 1953)], $\sigma: 175-847 \mathrm{~nm}$ (Ackerman 1971), $\sigma$ : 185-350 nm (Ozone Atmosphere 1985), $\sigma: 185-350 \mathrm{~nm}$ $\phi<280 \mathrm{~nm}$ (Kaufmann et al. 2003), $\phi>280 \mathrm{~nm}$ (Sander et al. 2006). The $k_{3}, a_{2}, a_{6}, a_{6 b}, b_{4}, b_{9}, d_{2}, e_{2}$ and $k_{2}(\mathrm{M})$ are the chemical rate constants of the reactions and are taken from (Sander et al. 2006).

A polar stratospheric cloud parametrisation scheme is incorporated in the model. It is activated when the cosine of the solar zenith angle is larger than zero at stratospheric altitudes and the stratospheric temperature drops below $195 \mathrm{~K}$ (Neale et al. 2012).

The starting values of the zonal mean climatology of the local $\mathrm{O}_{3}$ concentration, the temperature, the overhead column $\mathrm{O}_{3}$ and other chemicals used by the model are based on satellite and in situ Earth observations (Neale et al. 2012). A detailed model description can be found in Neale et al. (2012).

\section{Methods}

\section{Simulation setup}

We perform two simulations, one for the PDE with a rotation rate of $\Omega_{\mathrm{PDE}}=1\left(\frac{\text { rotation }}{\text { days }}\right)$ and a second one for the TLE with a rotation rate of $\Omega_{\mathrm{TLE}}=\frac{1}{365}\left(\frac{\text { rotation }}{\text { days }}\right)$. Therefore, the TLE rotation rate is $\left(\frac{1}{365}\right)$ th of the PDE rotation rate. The slow TLE rotation rate results in one side of TLE permanently facing the Sun-like star.

The Sun-Earth distance is $1 \mathrm{AU}$ in both cases, and the eccentricity is that of the present-day Earth on the day of the spring equinox. In our simulation, we use active, fully prognostic atmosphere and land geophysical models and a data ocean geophysical model. The solar irradiance at 
the top of the atmosphere is $S_{0}=1368.22 \mathrm{~W} / \mathrm{m}^{2}$ (Neale et al. 2012). The simulation begins on the day of the spring equinox (21.03.2000). The duration of the simulation is 90 days. Several model parameters are changed to obtain a tidally locked planet:

- the obliquity,

- the number of seconds in a sidereal day,

- the number of seconds the planet needs to rotate by 1 degree,

- the cosine of the solar zenith angle (SZA),

- the position of the subsolar point,

- the sea surface temperature (SST).

The TLE's obliquity is set to $0^{\circ}$ for the duration of the simulation. The number of seconds in a siderial day is altered from $86164 \mathrm{~s} /$ day to $3.15 \times 10^{7} \mathrm{~s} /$ day. As a result, the earth's rotation velocity changes from $8.43 \times 10^{-10} \mathrm{rad} / \mathrm{s}$ to $2.31 \times 10^{-12} \mathrm{rad} / \mathrm{s}$. The planet is set to rotate one degree every $87,600 \mathrm{~s}$ (the Earth rotates one degree every $240 \mathrm{~s}$ ). The SZA is set to a constant value by means of the PDE Julian date. By setting the Julian date to a constant value, the periodic 24-h variation of SZA is stopped at all grid points of the TLE. The SZA is the central parameter for the assessment of the incoming solar radiation in the CESM model world. The position of the subsolar point is set to remain constant at $\left(0.17^{\circ} \mathrm{N},-178.17^{\circ} \mathrm{E}\right)$, which is the position of the subsolar point at 00:00 UT on the spring equinox.

The subsolar point and the distribution of the shortwave solar radiation at the top of the model for the duration of the simulation are shown in Fig. 1. Shades of red indicate high incoming solar radiation on the day side of the planet, while shades of blue indicate low incoming solar radiation. The dark blue visible in the centre of the figure indicates zero incoming radiation on the night side of the planet. The subsolar point is indicated with a white point on either side of Fig. 1. It is centred approximately at $\left(0^{\circ}, 80^{\circ}\right)$ over the Pacific Ocean. The antisolar point is indicated with a magenta point in the centre of the figure and is centred approximately at $\left(0^{\circ}, 0^{\circ}\right)$.

The prescribed SST input dataset was altered to closely resemble the SST reported by Merlis and Schneider (2010), as shown in Fig. 2. The SST is highest at the subsolar point with a temperature $\approx 300 \mathrm{~K}$ and decreases monotonically and isotropically as one moves away from the subsolar point. The night side SST has a uniform value of $250 \mathrm{~K}$.

The continents and topography of the Earth were maintained as the use of the standalone atmospheric geophysical model CESM1(WACCM) without an active land model is not supported. We emphasise that the initialisation data are the same for both runs. This means that the TLE simulation run starts with the same 3D ozone and wind field as the PDE simulation run.

Although the possibility of tidal locking of an Earthlike planet within the habitable zone of a Sun-like star is low, the existence of Venus shows that a slow rotating planet is possible. As mentioned in the "Introduction", Yang et al. (2014) demonstrated that very slowly rotating and tidally locked planets located at a distance of $0.7 \mathrm{AU}$ from a Sun-like star can maintain an Earth-like atmosphere despite their close distance to the parent star. Their models were designed for tropospheric simulations and lacked the full stratospheric chemistry and resolution available in CESM1(WACCM). Furthermore, several past studies of tidally locked exoplanets orbiting $\mathrm{M}$ stars used models with solar spectrums and atmospheric compositions similar to that of the PDE (Merlis and Schneider

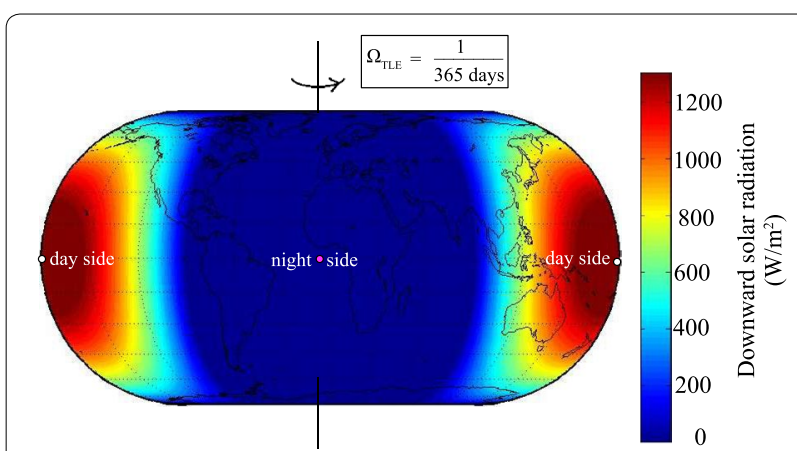

Fig. 1 Simulation setup. Downward shortwave top of the model flux setup for the TLE simulation. The subsolar point is indicated with a white point and the antisolar point with a magenta point. Shades of red indicate high incoming solar radiation and define the day side of the planet. Shades of blue indicate low incoming solar radiation. The dark blue visible in the centre of the plot indicates the absence of incoming solar radiation and defines the night side of the planet

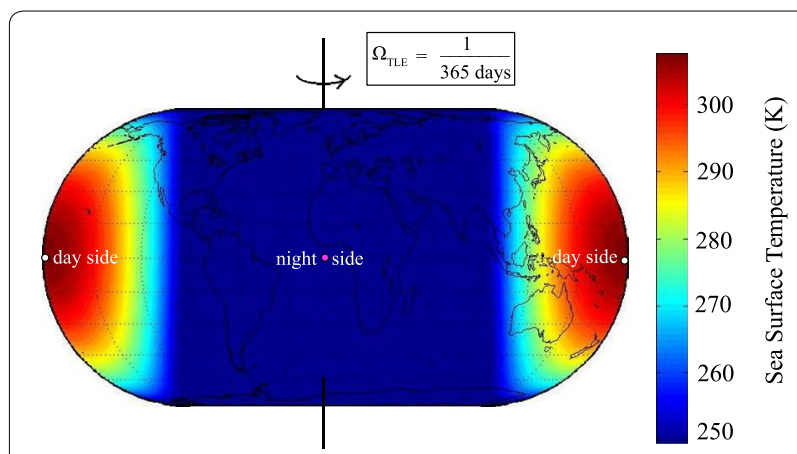

Fig. 2 Sea surface temperature. Tidally locked Earth SST. The subsolar point is indicated with a white point and the antisolar point with a magenta point. Shades of red indicate high temperatures and define the day side of the planet. Shades of blue indicate low temperature and define the night side of the planet. The subsolar point is indicated with a white point on either side of the figure. The antisolar point is indicated with a magenta point in the centre of the figure 
2010; Joshi 2003; Yang et al. 2013; Edson et al. 2011; Kaspi and Showman 2015; Menou 2013). Our method therefore also fosters the intercomparison and interpretation of the differences with these past models. Lastly the use of the Earth's starting atmospheric composition for our simulations simplifies the intercomparison and interpretation of the differences between the PDE and TLE model runs.

\section{Ensemble simulation}

To verify the validity of our results, an ensemble simulation with 5 runs is performed. This is the typical sensitivity setup used in atmospheric physics simulation studies. The first two runs are set 5 and 10 days before the spring equinox, respectively. One run is set on the day of the spring equinox. The last two runs are set 5 and 10 days after the spring equinox, respectively. The main features of the simulation, described in detail in the "Results and discussion" section, are present in the ensemble average and in each individual run, with the extent of the enhanced and depleted TOC $\mathrm{TLE}$ regions varying slightly, in accordance with the variability of the starting conditions. The deviation from the ensemble average is of the order of $\sim 1 \%$ and is given in Table 1 .

\section{Data analysis}

The $\mathrm{O}_{3}$ volume mixing ratio $\left(\mathrm{O}_{3} \mathrm{VMR}\right)$, the air density and the zonal, meridional and vertical wind as well as the downward shortwave flux are extracted from the output datasets of the simulation run. As a first step, the above parameters are interpolated for the altitudes of 1 to 140 $\mathrm{km}$ with a variable step $1.7<$ step $<104 \mathrm{~km}$. Then the $\mathrm{O}_{3}$ concentration is calculated by multiplying the $\mathrm{O}_{3}$ volume mixing ratio with the air number density $\left[\mathrm{O}_{3}\right]=\mathrm{O}_{3 V M R} \times$ [air]. It is useful to note that trace gases like ozone and atomic oxygen are usually given in volume mixing ratio (VMR).

As a next step, the POCs (partial ozone column densities) for the troposphere and lower stratosphere, middle stratosphere and mesosphere (5-28, 30-45 and

Table 1 Comparison of the deviation of the TOC ${ }_{\text {TLE }}$ global mean of the ensemble runs from the ensemble average

\begin{tabular}{lccc}
\hline $\begin{array}{l}\text { Date of the start } \\
\text { of the simulation }\end{array}$ & TOC $_{\mathrm{GM}}$ (DU) & Deviation (DU) & Deviation (\%) \\
\hline 11.03 & 245.3 & -2.01 & -0.93 \\
16.03 & 242.4 & 0.88 & 0.37 \\
21.03 & 244.1 & -0.8 & -0.33 \\
26.03 & 243.5 & -0.22 & 0.08 \\
31.03 & 243.6 & -0.35 & 0.12 \\
Ensemble average & 243.3 & 0 & 0 \\
\hline
\end{tabular}

$55-100 \mathrm{~km})$ are calculated by interpolating the $\mathrm{O}_{3}$ concentration from the lower to the higher limits for each case; $\quad \mathrm{POC}_{5-28}=\int_{5}^{28}\left[\mathrm{O}_{3}\right] d z, \quad \mathrm{POC}_{30-45}=\int_{30}^{45}\left[\mathrm{O}_{3}\right] d z$, $\mathrm{POC}_{55-110}=\int_{55}^{110}\left[\mathrm{O}_{3}\right] d z$.

Due to the presence of several high mountains and mountain ranges (e.g. Himalayas and Kilimanjaro) and data gaps in the air density parameter above the altitude of $110 \mathrm{~km}$, we calculate the TOC between the altitudes of 5 and $110 \mathrm{~km}\left(\mathrm{TOC}=\int_{5}^{110}\left[\mathrm{O}_{3}\right] d z\right)$.

As a next step, the global means of the TOC and POCs are calculated by calculating their zonal means as a function of latitude and then weighting them with the surface area of the latitude belts (surface area preserving mean). Then, the change in percentages of TOC and POC between the PDE and TLE is calculated.

$$
\begin{aligned}
& \Delta \mathrm{TOC}_{\%}=\frac{\mathrm{TOC}_{\mathrm{TLE}}-\mathrm{TOC}_{\mathrm{PDE}}}{\mathrm{TOC}_{\mathrm{PDE}}} \times 100 \\
& \Delta \mathrm{POC}_{\%}=\frac{\mathrm{POC}_{\mathrm{TLE}}-\mathrm{POC}_{\mathrm{PDE}}}{\mathrm{POC}_{\mathrm{PDE}}} \times 100 \\
& \Delta \mathrm{TOC}_{\mathrm{DU}}=\mathrm{TOC}_{\mathrm{TLE}}-\mathrm{TOC}_{\mathrm{PDE}} \\
& \Delta \mathrm{POC}_{\mathrm{DU}}=\mathrm{POC}_{\mathrm{TLE}}-\mathrm{POC}_{\mathrm{PDE}}
\end{aligned}
$$

Lastly, we calculate the hemisphere means (HM) of PDE and TLE (TOC $\left.\mathrm{HM(PDE)}, \mathrm{TOC}_{\mathrm{HM} \text { (TLE) }}\right)$ as well as their differences $\left(\triangle \mathrm{TOC}_{\mathrm{HM} \text { (PLE,TLE) }} \Delta \mathrm{TOC}_{\mathrm{HM} \text { (TLE,TLE), }}\right.$ $\left.\triangle \mathrm{TOC}_{\mathrm{HM}(\mathrm{PDE}, \mathrm{PDE})}\right)$. The TOC hemisphere mean is the TOC mean of one side of the planet, which spans $180^{\circ}$ in longitude and $180^{\circ}$ in latitude. First, the hemisphere TOC zonal mean is calculated as a function of latitude and then weighed with the surface area of the hemisphere latitude belts (surface area preserving mean). $\triangle \mathrm{TOC}_{(\mathrm{PLE}, \mathrm{TLE})}$ is the difference between the hemisphere mean of the TLE and PDE. The $\triangle \mathrm{TOC}_{\text {(TLE,TLE) }}$ is the difference between the TLE hemisphere centred around the $0^{\circ}$ meridian and the hemisphere centred around the $\phi$ meridian (where $0^{\circ}<\phi<360^{\circ}$ ). The $\Delta \mathrm{TOC}_{(\mathrm{PDE}, \mathrm{PDE})}$ is the difference between the PDE hemisphere centred around the $0^{\circ}$ meridian and the hemisphere centred around the $\phi$ meridian.

$$
\begin{aligned}
\Delta \mathrm{TOC}_{\mathrm{HM}(\mathrm{PLE}, \mathrm{TLE})} & =\frac{\mathrm{TOC}_{\mathrm{HM}(\mathrm{PDE})}-\mathrm{TOC}_{\mathrm{HM}(\mathrm{TLE})}}{\operatorname{TOC}_{\mathrm{HM}(\mathrm{TLE})}} \\
\Delta \mathrm{TOC}_{\mathrm{HM}(\mathrm{TLE}, \mathrm{TLE})} & =\frac{\operatorname{TOC}_{\mathrm{HM}\left(\mathrm{TLE}\left(0^{\circ}\right)\right)}-\mathrm{TOC}_{\mathrm{HM}(\mathrm{TLE}(\phi))}}{\operatorname{TOC}_{\mathrm{HM}(\mathrm{TLE}(\phi))}} \\
\Delta \mathrm{TOC}_{\mathrm{HM}(\mathrm{PDE}, \mathrm{PDE})} & =\frac{\operatorname{TOC}_{\mathrm{HM}\left(\operatorname{PDE}\left(0^{\circ}\right)\right)}-\mathrm{TOC}_{\mathrm{HM}(\operatorname{PDE}(\phi))}}{\operatorname{TOC}_{\mathrm{HM}(\operatorname{PDE}(\phi))}}
\end{aligned}
$$




\section{Terminology}

A tidally locked planet can be divided into the day side and the night side. The day side is the permanently illuminated hemisphere that is always facing the parent star. The position of the maximum solar flux, located at the centre of the day side, is the subsolar point. The night side is the hemisphere that is never illuminated by the parent star. The position at the centre of the night side, located $180^{\circ}$ away from the subsolar point, is the antisolar point. The border region of these two hemispheres, the terminator (Tarter et al. 2007), is located $90^{\circ}$ away from the subsolar and antisolar points and stretches from the North to the South Pole. This region can be divided into the dawn terminator region (located $90^{\circ}$ to the West of the subsolar point) and the dusk terminator region (located $90^{\circ}$ to the East of the subsolar point).

The VMR gives the amount of a trace gas in parts per million (ppmv), e.g. 10 ppmv means 10 ozone molecules per 1 million air molecules. The TOC is measured in Dobson units (DU). One Dobson unit "refers to a layer of gas that would be $10 \mu \mathrm{m}$ thick under standard temperature and pressure" (Liu et al. 2007) and is equal to $2.6910^{16}$ ozone molecules $/ \mathrm{cm}^{2}$, or $2.6910^{20}$ ozone molecules $/ \mathrm{m}^{2}$ (Liu et al. 2007).

\section{Results and discussion}

\section{Atmospheric steady state}

The middle atmosphere of the TLE adjusts to the new conditions within 80 days. The adjustment times of the TLE total ozone column (TOC $\mathrm{TLE}$ ), the global mean horizontal wind ( $\left.\mathrm{HW}_{\mathrm{TLE}}\right)$, the global mean vertical wind (VW $\left.{ }_{\text {TLE}}\right)$ and the global mean stratospheric temperature $\left(\mathrm{T}_{\text {strat(TLE) }}\right)$ to the new tidally locked conditions are shown in Fig. 3. The HW TLE, VW TLE and $\mathrm{T}_{\text {strat(TLE) }}$ are calculated for the altitude region of 30-40 km altitude. In the figure, the temporal evolution of the PDE's TOC $\mathrm{PDE}_{\mathrm{P}}, \mathrm{HW}_{\mathrm{PDE}}$, $\mathrm{VW}_{\text {PDE }}$ and $\mathrm{T}_{\text {strat(PDE) }}$ is also shown for comparison.

The steady atmospheric state is reached at double the e-folding time, which is the time interval in which an exponentially decreasing quantity decreases by a factor of e. The e-folding times of the aforementioned parameters along with their steady-state mean values and their standard deviations are presented in Table 2. A comparison between the TLE and the standard deviations of the
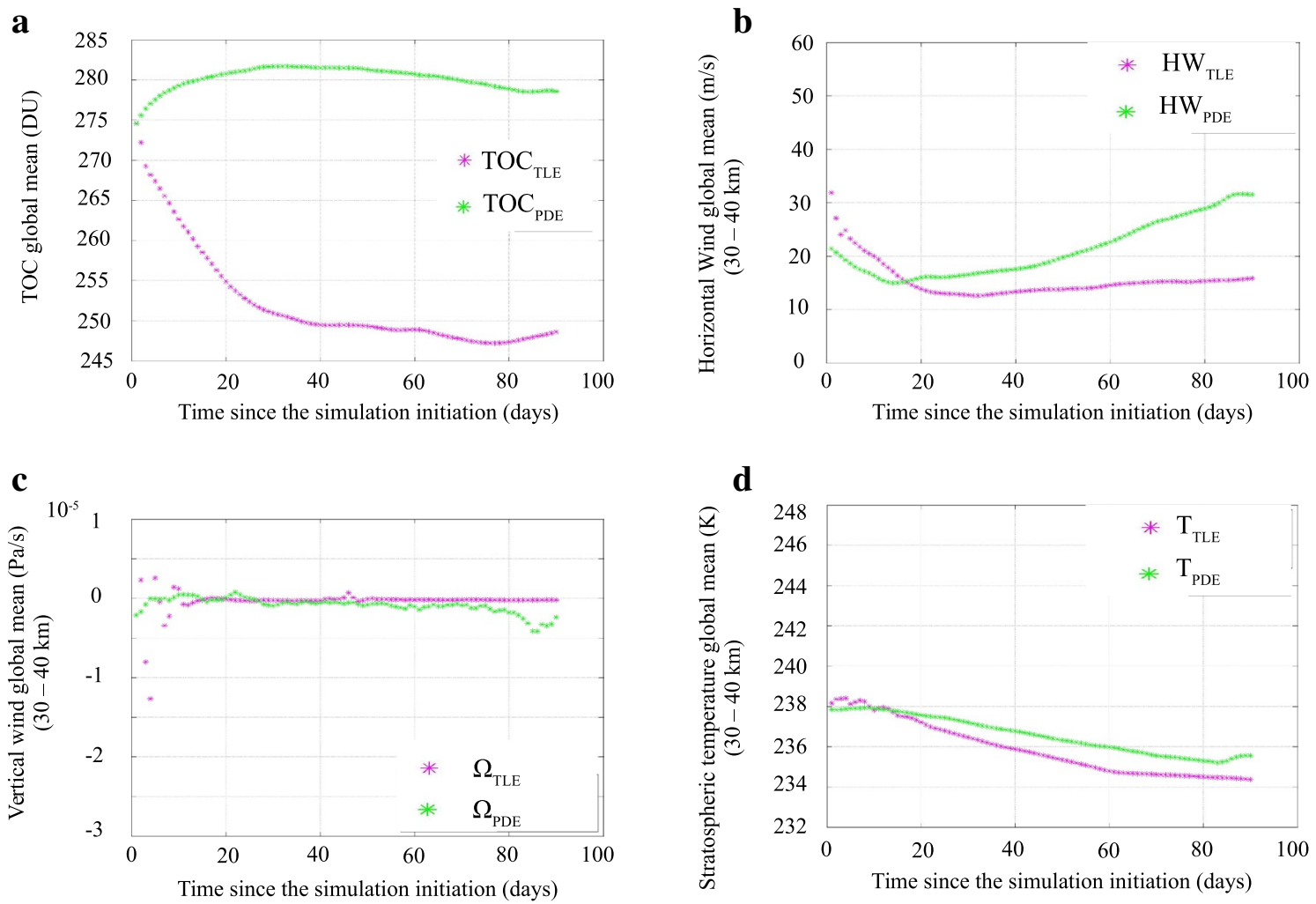

Fig. 3 Temporal evolution of the TLE and PDE atmospheres. a The TOC, $\mathbf{b}$ the HW, $\mathbf{c}$ the $\mathrm{VW}$ and $\mathbf{d} \mathrm{T}_{\text {strat, }}$ respectively. The TOC, HW, and Tstrat of the TLE are exponentially decaying to their steady-state value with an e-folding time of 30, 15 and 20 days, respectively. The VW of the TLE is exponentially increasing to its steady-state value with an e-folding time of 15 days 
Table 2 Comparison of the TOC and POC e-folding times, steady-state mean values and their standard deviations obtained for the PDE on the first day of the simulation and for the TLE on the 90th day of the simulation

\begin{tabular}{lllll}
\hline & PDE & $\boldsymbol{\sigma}_{\text {PDE }}$ & TLE & $\boldsymbol{\sigma}_{\text {TLE }}$ \\
\hline $\mathrm{TOC}(\mathrm{DU})$ & 280.1 & 1.44 & 248.7 & 1.00 \\
$\mathrm{HW}(\mathrm{m} / \mathrm{s})$ & 21.19 & 5.21 & 14.21 & 1.00 \\
$\Omega(\mathrm{Pa} / \mathrm{s})$ & $-8.6 \times 10^{-7}$ & $9.6 \times 10^{-7}$ & $-1.7 \times 10^{-7}$ & $1.3 \times 10^{-7}$ \\
$T_{\text {strat }}(\mathrm{K})$ & 239.9 & 0.85 & 238.4 & 0.43 \\
\hline
\end{tabular}

PDE reveals that the PDE standard deviations are actually larger than that of the TLE.

The TOC ${ }_{\text {TLE }}, \mathrm{HW}_{\mathrm{TLE}}, \mathrm{VW}_{\mathrm{TLE}}$ and $\mathrm{T}_{\text {strat(TLE) }}$ have an e-folding time of $30,20,15$ and 40 days, respectively. Therefore, the steady state is reached in approximately 60 , 40, 30 and 80 days, respectively. A comparison between the PDE and the TLE adjustment times reveals that the middle atmosphere of the TLE adjusts to the new conditions within approximately 2.5 months with the global mean of total ozone maintaining a value of approximately 249 DU (Table 2).

\section{Ozone distribution}

The Earth has a primary, a secondary and a tertiary ozone layer, all of which are shown in Fig. 4a, b. They depict the ozone $\mathrm{O}_{3} \mathrm{VMR}$ distribution of the present-day Earth at 00:00 UT, on the day of the spring equinox (21.03.2000) along the prime and the $180^{\circ}$ meridian.

The primary ozone layer is located in the stratosphere between 20 and $50 \mathrm{~km}$ and displays a maximum in the vicinity of the tropics at an altitude of $34-36 \mathrm{~km}$ (Brasseur and Solomon 2005). It is present during both the daytime and the night-time, though a small $(<2 \%)$ diurnal variation has been detected (Sakazaki et al. 2013). The tropopause is characterised by altitude variations (visible in Fig. 4a, b). It is located at higher altitudes in the tropics and lower altitudes in the poles.

The secondary ozone layer is located in the mesosphere between 80 and $100 \mathrm{~km}$, with a maximum at $\sim 90 \mathrm{~km}$. As shown in Fig. 4a, b, the ozone is depleted during the daytime $(\sim 1 \mathrm{ppmv})$ compared to the night-time $(\sim 2.5-8$ ppmv) (Kaufmann et al. 2003; Marsh et al. 2002).

During daytime, the stratospheric and mesospheric molecular oxygen is photodissociated towards atomic oxygen by the solar UV radiation $(\lambda<242.4 \mathrm{~nm})$ :

$$
\left(J_{2}\right) ; \mathrm{O}_{2}+h v \rightarrow \mathrm{O}+\mathrm{O}
$$

It then recombines with molecular oxygen, through the three-body process recombination, to produce ozone.

$$
\left(k_{2}\right) ; \mathrm{O}+\mathrm{O}_{2}+\mathrm{M} \rightarrow \mathrm{O}_{3}+\mathrm{M}
$$
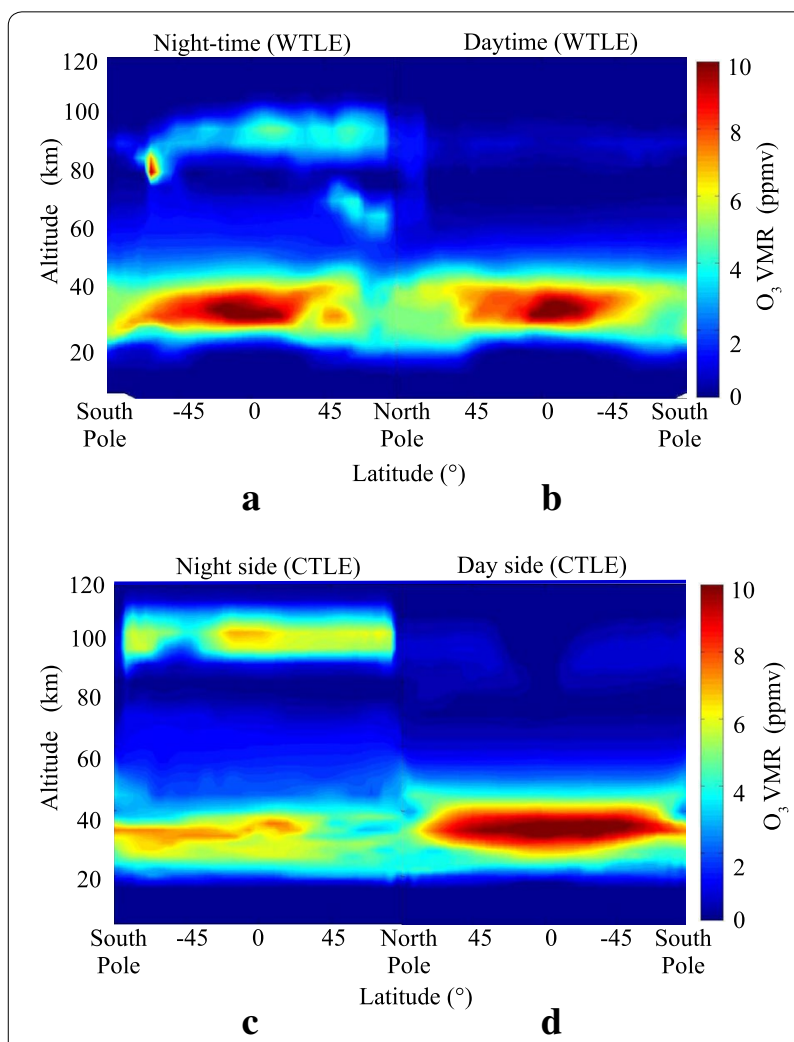

Fig. 4 Height-latitude cross section of $\mathrm{O}_{3}$ VMR along the meridian through the subsolar point and the antisolar point for the PDE and TLE. Vertical cross sections of $\mathbf{a}$ the PDE night-time hemisphere, $\mathbf{b}$ the PDE daytime hemisphere, $\mathbf{c}$ the TLE night side hemisphere and $\mathbf{d}$ the TLE day side hemisphere

$\mathrm{M}$ is a third body catalyst needed for the conservation of energy and momentum. In the stratosphere, the ozone generated through reaction 9 is photodissociated towards atomic oxygen by the $\mathrm{UV}$ radiation $(\lambda<320 \mathrm{~nm})$ (Fig. 4b).

$$
\left(J_{3}\right) ; \mathrm{O}_{3}+h v \rightarrow \mathrm{O}_{2}+\mathrm{O}
$$

Due to the high air and molecular oxygen density, $\mathrm{O}_{2}$ and $\mathrm{O}$ rapidly recombine to form ozone through reaction 9 . As a result, the stratospheric diurnal variation is of the order of $2 \%$ (Fig. 4a, b).

In the mesosphere, the generated ozone is either photodissociated by the $\mathrm{UV}$ radiation $(\lambda<320 \mathrm{~nm})$ towards atomic oxygen through reaction 10 or converted to $\mathrm{O}_{2}$ through a two-body collision with atomic oxygen.

$$
\left(k_{3}\right) ; \mathrm{O}+\mathrm{O}_{3} \rightarrow 2 \mathrm{O}_{2}
$$

During the night-time, the absence of UV radiation results in the increase in the mesospheric ozone through reaction 9 and the emergence of the secondary ozone layer (Fig. 4a). 
Ozone is destroyed not only through photodissociation by the incident UV radiation and interaction with $\mathrm{O}$, but also through catalytic cycles with $\mathrm{NO}$ and $\mathrm{OH}$. In the middle stratosphere (Wallas and Hobbs 2006), $\mathrm{O}_{3}$ is destroyed by NO through the following reactions

$$
\begin{gathered}
\mathrm{NO}+\mathrm{O}_{3} \rightarrow \mathrm{NO}_{2}+\mathrm{O}_{2} \\
\mathrm{NO}_{2}+\mathrm{O} \rightarrow \mathrm{NO}+\mathrm{O}_{2}
\end{gathered}
$$

This catalytic cycle is most efficient between 35 and 45 $\mathrm{km}$ (Brasseur and Solomon 2005). It is the most important ozone depletion cycle in the stratosphere. In the middle and upper stratosphere (Brasseur and Solomon 2005), $\mathrm{O}_{3}$ is destroyed through the following reactions

$$
\begin{gathered}
\mathrm{OH}+\mathrm{O}_{3} \rightarrow \mathrm{HO}_{2}+\mathrm{O}_{2} \\
\mathrm{HO}_{2}+\mathrm{O} \rightarrow \mathrm{OH}+\mathrm{O}_{2}
\end{gathered}
$$

Below $30 \mathrm{~km}$ (Wallas and Hobbs 2006) and close to the troposphere (Brasseur and Solomon 2005), $\mathrm{O}_{3}$ is destroyed through interaction with $\mathrm{OH}$

$$
\begin{aligned}
\mathrm{OH}+\mathrm{O}_{3} & \rightarrow \mathrm{HO}_{2}+\mathrm{O}_{2} \\
\mathrm{HO}_{2}+\mathrm{O}_{3} & \rightarrow \mathrm{OH}+2 \mathrm{O}_{2}
\end{aligned}
$$

In the same altitude range, the reactions

$$
\begin{aligned}
\mathrm{OH}+\mathrm{O} & \rightarrow \mathrm{H}+\mathrm{O}_{2} \\
\mathrm{H}+\mathrm{O}_{2}+\mathrm{M} & \rightarrow \mathrm{HO}_{2}+\mathrm{M} \\
\mathrm{HO}_{2}+\mathrm{O}_{3} & \rightarrow \mathrm{OH}+2 \mathrm{O}_{2}
\end{aligned}
$$

and

$$
\begin{aligned}
\mathrm{OH}+\mathrm{O} & \rightarrow \mathrm{H}+\mathrm{O}_{2} \\
\mathrm{H}+\mathrm{O}_{3} & \rightarrow \mathrm{OH}+\mathrm{O}_{2}
\end{aligned}
$$

are also responsible for the destruction of ozone (Brasseur and Solomon 2005).

In the mesosphere, ozone is destroyed primarily by $\mathrm{OH}$ (Brasseur and Solomon 2005).

$$
\begin{gathered}
\mathrm{OH}+\mathrm{O} \rightarrow \mathrm{H}+\mathrm{O}_{2} \\
\mathrm{H}+\mathrm{O}_{3} \rightarrow \mathrm{OH}+\mathrm{O}_{2}
\end{gathered}
$$

The quantities of atomic oxygen and ozone fluctuate during the day as a result of the rapid cycles of photolysis and recombination. However, their sum, also known as odd oxygen $\mathrm{O}_{x}$, remains almost constant. A reduction in ozone could indicate either the presence of a sink or an impermanent change towards atomic oxygen. A reduction in odd oxygen, on the other hand, reveals the presence of a permanent sink. Consequently, odd oxygen is used to discuss the generation and destruction of ozone in this paper.

The PDE possesses a tertiary night-time ozone layer, as shown in Fig. 4a, in the region between 60 and $80 \mathrm{~km}$ in the vicinity of the North Pole. It was first detected and modelled by Marsh et al. (2001) and is present only within a small region at high latitudes during night-time.

The atmosphere of the TLE has a vertical structure similar to the PDE, with a troposphere, stratosphere and mesosphere. However, the characteristics of these layers differ markedly from those of the PDE. Due to the tidal locking, the geographic locations of the daytime and night-time hemispheres are static.

Figure 4c, d depict the $\mathrm{O}_{3} \mathrm{VMR}$ distribution of the TLE along the meridians intersecting the antisolar and subsolar points, respectively. The primary ozone layer on the day side of the TLE (Fig. 4d) is characterised by a higher $\mathrm{O}_{3}$ VMR and a wider coverage area compared to the daytime equivalent of the PDE (Fig. $4 \mathrm{~b}$ ). The primary ozone layer on the night side of the TLE (Fig. 4c), on the other hand, appears depleted compared to its PDE night-time equivalent (Fig. 4b). Since the production of odd oxygen requires shortwave radiation, the night side displays a reduced ozone concentration compared to the day side. The day-night side variation of the TLE primary ozone layer is $\sim 40 \%$, one order of magnitude larger than that of the PDE $(<2 \%)$. The global mean altitude averaged middle atmospheric horizontal wind is $13.2 \mathrm{~m} / \mathrm{s}$ on the TLE and $27.5 \mathrm{~m} / \mathrm{s}$ on the PDE.

The enhanced day-night side variation can be explained by this reduction in the transport velocities of the ozone, from the day side to the night side of the TLE stratosphere compared to the PDE stratosphere, as well as the static locations of the daytime and night-time hemispheres. The primary TLE ozone layer is also characterised by altitude variations (Fig. 4c, d), which are present in both the day side and the night side, but are much less pronounced compared to the PDE (Fig. 4a, b).

The secondary ozone layer of the TLE is shown in Fig. 4c, d. As in the case of the rotating Earth (PDE), the secondary ozone layer is only present during night-time. The formation mechanism of the secondary ozone layer on the TLE is similar to that of the observed night-time ozone layers present in both the Earth's mesosphere and the upper atmosphere of Venus (Montmessin et al. 2011).

The $\mathrm{O}_{3}$ VMR of the TLE day side (Fig. $4 \mathrm{~d}$ ) is similar to the daytime PDE primary ozone layer (Fig. 4b). The TLE night side secondary ozone layer (Fig. 4c) is characterised by an enhanced $\mathrm{O}_{3}$ VMR compared to the PDE nighttime (Fig. 4d, a, respectively). This is due to the transport of odd oxygen from the day side to the night side through both the horizontal and vertical circulation, where it recombines to form ozone. The transport of air from the day side to the night side in the $55-100 \mathrm{~km}$ altitude region through the horizontal circulation and the vertical circulation is shown in Figs. 6 and 8, respectively. 
The TLE does not possess a tertiary night-time ozone layer as shown in Fig. 4c. The chemical and dynamical processes that cause the disappearance of the TLE tertiary ozone layer currently remain unclear. It could be related to the fact that the air is not rapidly brought from the day to the night side in the case of the TLE compared to the PDE.

\section{Atmospheric circulation}

The PDE stratospheric ozone distribution is determined by the atmospheric wave-driven Brewer-Dobson circulation, which is responsible for the transport of air from the equatorial troposphere to the stratosphere. As shown in Fig. 5, air rises from the tropical troposphere into the stratosphere. It is then transported towards the poles and descends back into the troposphere at middle and high latitudes, following the conservation of mass law (Andrews 2010; Müller 2012). Due to the land-ocean distribution differences in the Southern and Northern Hemisphere, the Brewer-Dobson circulation differs in the two hemispheres, with a much stronger Southern winter polar vortex compared to the Northern winter polar vortex. As a result, the horizontal mixing seldom reaches the Antarctic region and is confined in lower latitudes in the Southern Hemisphere. In the Northern Hemisphere, on the other hand, the horizontal mixing often reaches the North Pole region (Müller 2012).

On the TLE, the vertical air transport is achieved through a different mechanism, as a result of the breakdown of the Brewer-Dobson circulation, which is shown in Figs. 6, 7 and 8. The middle atmospheric wind system

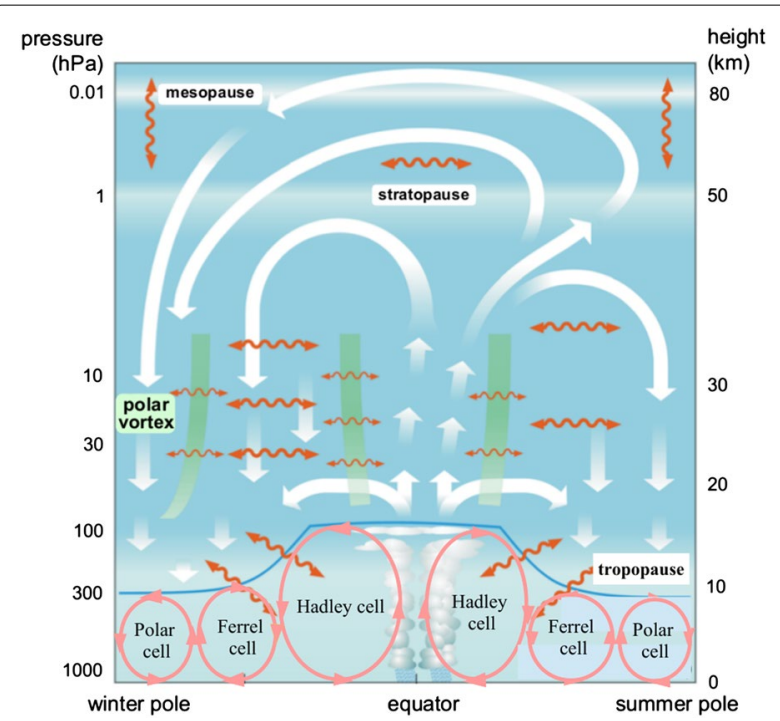

Fig. 5 The Brewer-Dobson circulation in the PDE. The Hadley, Ferrel and Polar cells are visible in the figure for both hemispheres. Adapted from Bönisch et al. (2011) of the TLE shows a high degree of spatio-temporal variability, with the direction and location of the TLE jet stream completely changing over height intervals of the order of $10 \mathrm{~km}$ (Fig. 6).

Figure 6 shows the zonal mean of the zonal wind for the PDE (Fig. 6a) and the TLE (6b), from 5 to $110 \mathrm{~km}$ altitude. A comparison between the two figures reveals that the TLE zonal mean zonal wind is markedly different from the PDE equivalent. In the PDE, the southward air motion contributes to the geostrophic zonal wind. On the TLE, on the other hand, the air motion is southward in the Northern Hemisphere and northward in the Southern Hemisphere at tropospheric, middle stratospheric and mesospheric altitudes.

It is, therefore, clear that there is a tendency for the formation of only one jet stream over the globe with high wind speeds in the meridional or zonal direction at different altitudes.

In the lower stratosphere, atmospheric transport can occur over the poles or along the equator from the day side to the night side depending on the altitude.

The meridional wind zonal mean of the TLE is smaller compared to that of the PDE, possibly due to smaller horizontal gradients in the temperature field of the TLE and the lack of the overturning circulation cells at the poles.

Figure 7 shows the horizontal wind at the altitudes of $24 \mathrm{~km}$ (Fig. 7a), $36 \mathrm{~km}$ (Fig. 7b) and $60 \mathrm{~km}$ (Fig. 7c). As can be seen, the horizontal circulation differs greatly between different altitudes, and this applies to the entire atmosphere. It also differs from the equivalent PDE circulation, which is not shown here. At lower and middle stratospheric altitudes, jet streams are present, which encompass the entire globe with the strongest component located in the equator. At $20-35 \mathrm{~km}$ the jet stream is eastward, while at $35-40 \mathrm{~km}$ altitude the jet stream is westward, as shown in Fig. 7a, b. The strong natural variability of the lower stratospheric wind field leads to considerable periodic changes ( $\approx 15$ days) in the distribution patterns of the lower stratospheric ozone $(16-28 \mathrm{~km})$, while at the same time the global mean of total ozone is maintained. The PDE circulation at these altitudes is characterised by the presence of a westward equatorial jet stream and two eastward extratropical jet streams. At mesospheric altitudes, the meandering jet stream can transit into large-scale vortices as shown in Fig. 7c. In comparison, in the PDE the circulation is largely eastward in the Northern Hemisphere and westward in the Southern Hemisphere, with no vortices present.

The Brewer-Dobson circulation is replaced by an upwelling on the day side of the planet and a downwelling on the night side. The upwelling is centred in the subsolar point, while the downwelling is centred on the antisolar point. Both extend from the surface to the middle 


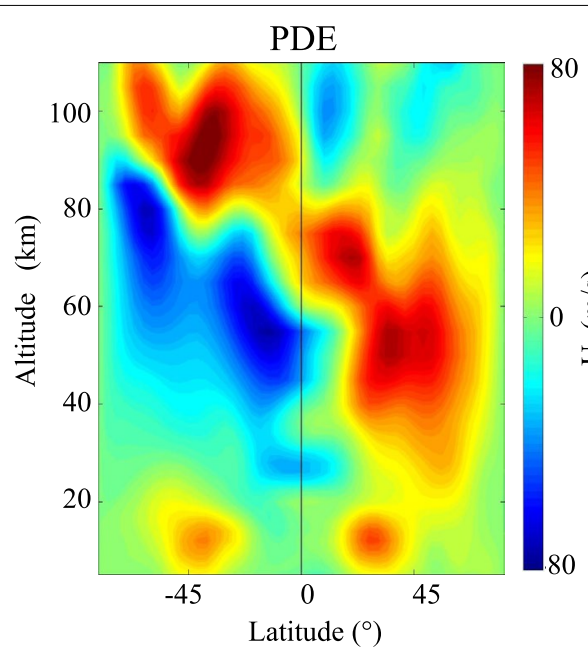

a

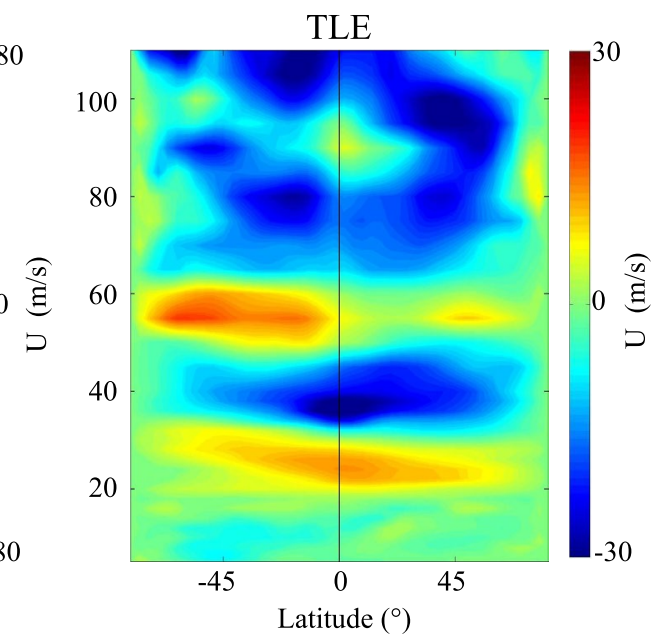

b

Fig. 6 Zonal mean zonal wind latitude-altitude plots of the PDE and TLE. a PDE, b TLE. Warm colours indicate movement from the west to the east, while cold colours indicate movement from the east to the west

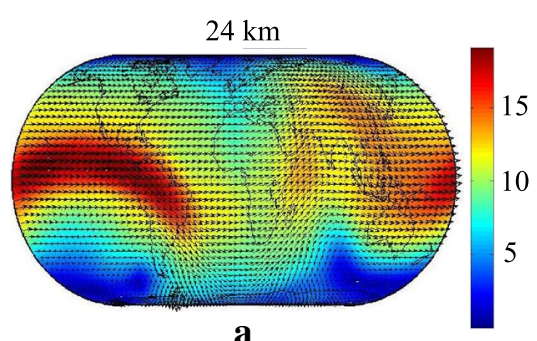

$\mathbf{a}$

$60 \mathrm{~km}$
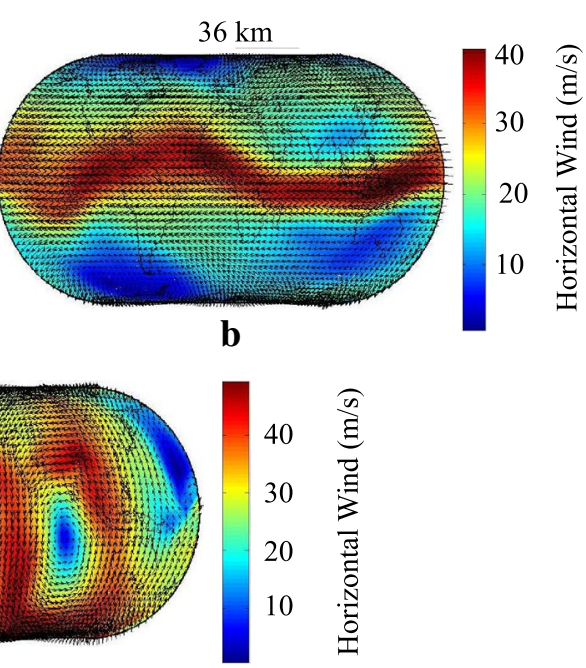

c

Fig. 7 Horizontal circulation of the TLE at select altitudes, $\mathbf{a}$ at $24 \mathrm{~km}, \mathbf{b}$ at $36 \mathrm{~km}, \mathbf{c}$ at $60 \mathrm{~km}$. The black arrows indicate the wind vector while the colour shading shows the wind speed. Warm colours indicate high wind speed, while cool colours indicate low wind speed

mesosphere. The day side receives a constant flux of solar radiation and is radiatively heated. The upward movement of the heated air creates the reported upwelling. The night side, on the other hand, receives no solar radiation and is, therefore, radiatively cooled with the cooler air sinking and creating the reported downwelling. However, compared to the PDE the TLE has a much smaller temperature gradient compared to the PDE, as shown in Fig. 9 for the altitude of $36 \mathrm{~km}$.

Merlis and Schneider (2010) also predicted the presence of an upwelling on the day side, centred on the subsolar point and a downwelling on the night side, centred over the antisolar point, in their simulated tidally locked aquaplanet troposphere. They also attributed the upwelling to radiative heating and the downwelling to radiative cooling.

\section{Mesospheric partial ozone column}

On the Earth's mesospheric daytime hemisphere, atomic oxygen is more abundant than ozone, so atomic oxygen can be used as a measure of odd oxygen $\left[\left(\mathrm{O}_{x}\right) \approx(O)\right]$. Figure 10a depicts the PDE mesospheric POC 


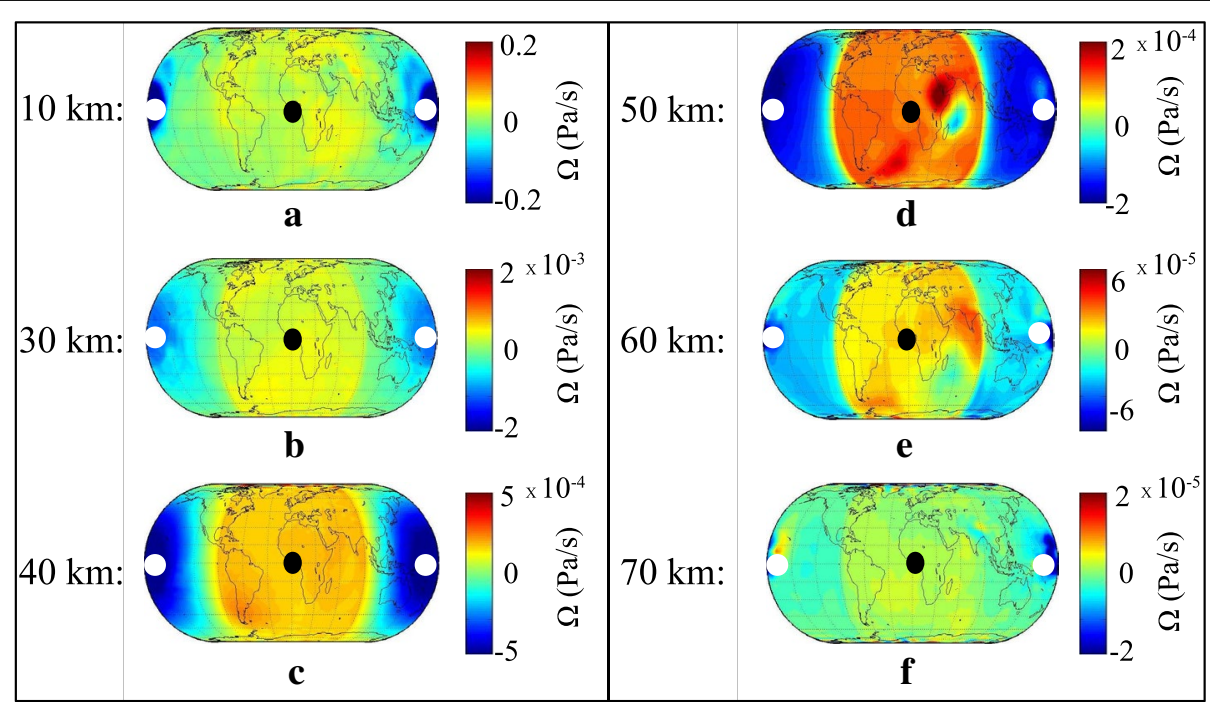

Fig. 8 Longitude-latitude vertical wind circulation on the TLE. Vertical wind at a $10 \mathrm{~km}, \mathbf{b} 30 \mathrm{~km}, \mathbf{c} 40 \mathrm{~km}, \mathbf{d} 50 \mathrm{~km}, \mathbf{e} 60 \mathrm{~km}$ and $\mathbf{f} 70 \mathrm{~km}$. Warm colours (positive values) indicate a downwelling wind. Cold colours (negative values) indicate an upwelling wind. Each figure is centred on the antisolar point, which is indicated with a black dot. The subsolar point is indicated with a white dot on either side of each figure

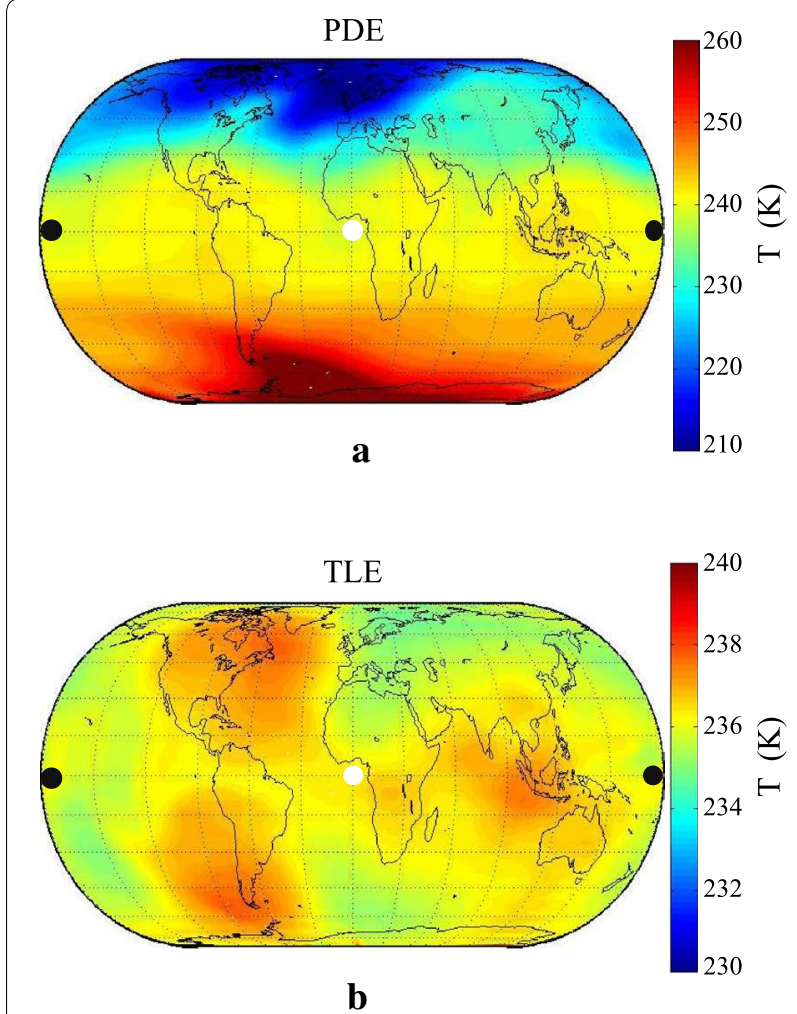

Fig. 9 Comparative view of the PDE and TLE atmospheric tempera-

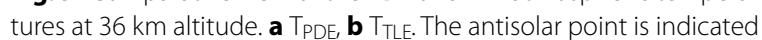
with a white point. The subsolar point is indicated with a black point. The middle stratospheric TLE temperature is clearly decreased compared to the PDE
$\left[\mathrm{POC} \mathrm{PDE}_{(55-110)]}\right.$ at 00:00 UT on the day of the spring equinox. The ozone is depleted on the daytime side of the planet and enhanced on the night-time side of the planet. A sharp transition region exists between the daytime and the night-time hemispheres. The odd oxygen is partitioned towards atomic oxygen on the daytime and towards ozone on the night-time hemisphere. At these altitudes, the lifetime of odd oxygen ranges between a few hours at $55 \mathrm{~km}$ to $\sim 1$ month at $95 \mathrm{~km}$. After sunset, the atomic oxygen rapidly recombines to form ozone as shown in Fig. 10a. The mean PDE night side POC is 0.40 DU, and the mean PDE day side POC is 0.23 DU. Therefore, the PDE mesospheric diurnal variation is $\sim 74 \%$ with respect to the daytime.

On the TLE, the night-time mesospheric ozone is well mixed from the equator to the poles (Fig. 10e). The day side ozone is visibly depleted due to the tidal locking, with $\mathrm{O}_{2}$ and $\mathrm{O}_{3}$ constantly photodissociated towards odd oxygen. Due to its long lifetime, odd oxygen is then transported through the horizontal circulation, as shown in Fig. 6, from the day to the night side where it recombines to form ozone. The ozone is further enhanced by the transportation of odd oxygen-rich air to the night side through the vertical circulation, by means of an upwelling centred over the subsolar point and then a downwelling centred on the antisolar point, where it recombines to form ozone. Consequently, the POC appears enhanced on the night side compared to its PDE counterpart. From Fig. 10e, we determined that on the TLE the mean night 


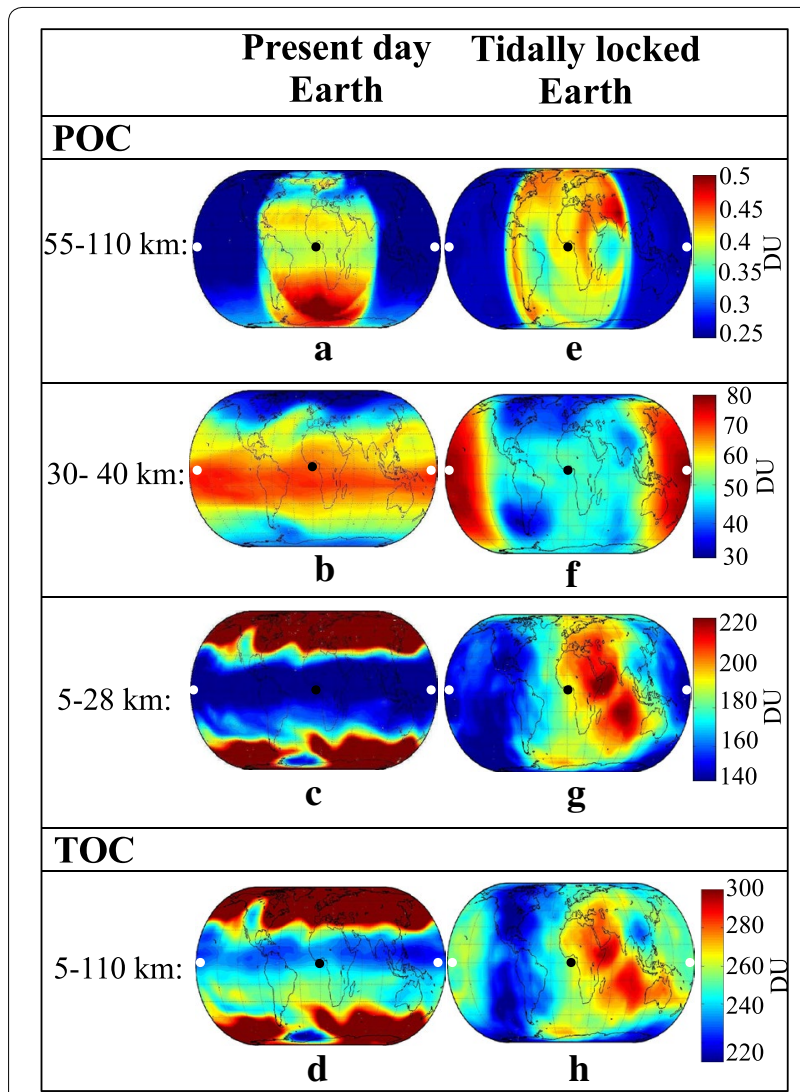

Fig. 10 Comparative TOC and POC maps for the PDE and the TLE. a POC $P D E(55-110)$, b POC $P D E(30-45)$, C POC $_{P D E(5-28),}$ d TOC PDE at 00:00 UT on the day of the spring equinox, respectively. ePOC TLE(55-110), $\mathbf{f} P O C_{T L E(30-45),} \mathbf{g P O C} T L E(5-28)$ and $\mathbf{h} \mathrm{TOC}_{T L E}$ on the 90th day of the TLE simulation, respectively. All figures are centred on the antisolar point, which is indicated with a black dot. The subsolar point is indicated with a white dot on either side of each figure

side POC is $0.40 \mathrm{DU}$ and the mean day side POC is 0.28 DU. Therefore, the TLE mesospheric day-night side variation is $\sim 43 \%$ with respect to the day side. This is a considerable decrease compared to its PDE counterpart.

\section{Stratospheric partial ozone column}

Ozone is much more abundant than atomic oxygen in the Earth's stratosphere. Therefore, in the stratosphere odd oxygen is used as a measure of ozone $\left(\left(\mathrm{O}_{x}\right) \approx\left(\mathrm{O}_{3}\right)\right)$.

\section{Middle stratospheric partial ozone column}

The middle stratosphere of the PDE ranges from 30 to $45 \mathrm{~km}$ and is the region with the highest stratospheric $\mathrm{O}_{3} \mathrm{VMR}$. At these altitudes, the ozone distribution is governed mainly by the photochemistry and to a smaller degree by the dynamics. Odd oxygen is mainly generated during the daytime through the photolysis of molecular oxygen (reaction 8 ) and has an average lifetime of $\tau_{\mathrm{O}_{x}} \sim$
16.5 days. It is destroyed during the night-time through recombination with atomic oxygen (reaction 11) and catalytic chemical reactions by $\mathrm{NO}$ and $\mathrm{OH}$ (Brasseur and Solomon 2005).

In Fig. 10b, the Earth's middle stratospheric ozone is displayed. The increased solar radiation flux that the equatorial latitudes receive leads to enhanced ozone generation. Due to its relatively long lifetime, as well as the strong Coriolis force, odd oxygen remains enhanced during the night-time and, therefore, displays a small diurnal variation $(<5 \%)$ (Sakazaki et al. 2013). As shown in Fig. 10b, the POC has a zonal latitudinal dependence as a result of the strong Coriolis force, which creates a mixing barrier. Consequently, the middle stratospheric POC $\left(\mathrm{POC}_{\mathrm{PDE}(30-45)}\right)$ is enhanced in the tropics and depleted in the poles.

In Fig. 10f, the middle stratospheric ozone of the TLE is displayed. On the TLE, ozone is only generated on the day side. It is transported to the night side through the horizontal circulation. On the night side, ozone is depleted through reactions with $\mathrm{O}$ and catalytic cycles. The global mean transport velocities between the day and the night side of the middle stratosphere $(13 \mathrm{~m} / \mathrm{s})$ are smaller by $47 \%$ compared to the mesosphere $(25 \mathrm{~m} / \mathrm{s})$, so the mixing between the day and the night side occurs at a slower rate. Furthermore, the middle stratospheric global mean temperature is reduced on the TLE compared to the PDE as shown in Fig. 9. As a consequence, the ozone generation rates on the day side will be increased, resulting in a visibly enhanced POC. On the night side, a combination of the lack of shortwave radiation flux, increased destruction rates and slow transport velocities leads to a visibly depleted night side POC and a high day-night side difference. The above effects are further enhanced by the large-scale meridional mixing due to the small Coriolis force. As shown in Fig. 10f, the mean night side POC is $45 \mathrm{DU}$, while the mean day side POC is $58 \mathrm{DU}$. Therefore, the day-night side middle stratospheric ozone variation of the TLE is $\sim 29 \%$ with respect to the night side, one order of magnitude larger than the PDE middle stratospheric diurnal variation.

\section{Lower stratospheric and tropospheric partial ozone column}

The PDE lower stratosphere ranges from 14 to $28 \mathrm{~km}$. The troposphere ranges from the surface to approximately 14 $\mathrm{km}$. Figure 10c displays the PDE lower stratospheric and tropospheric $\mathrm{POC}\left(\mathrm{POC}_{\mathrm{PDE}(5-28))}\right.$. At these altitudes, the odd oxygen (and, therefore, ozone) has a lifetime of several months due to the attenuation of the UV radiation flux at higher altitudes. As a result, the ozone distribution is influenced mainly by the dynamics. The Brewer-Dobson circulation transports ozone-rich air from the midstratosphere to the polar regions, where the overturning 
circulation cell shifts the ozone-rich air into the lower polar stratosphere (Brasseur and Solomon 2005) where it accumulates. The PDE lower stratospheric diurnal variation is $\sim 0.1 \%$, which is in agreement with the diurnal variation observed by the SMILES experiment on the International Space Station (Sakazaki et al. 2013). On the $\mathrm{PDE}$, the tropospheric $\left[\mathrm{O}_{3}\right]$ is lower by an order of magnitude compared to the stratosphere and, therefore, does not contribute considerably to the $\mathrm{POC}_{\mathrm{PDE}(5-28) \text {. }}$

In the lower stratosphere of the TLE, the ozone, which was concentrated in extratropical latitudes at the start of the simulation, was transported through the horizontal and vertical circulation to the night side of the planet where it accumulated, generating the high levels of ozone visible in the Southern night side. Furthermore, any ozone generated on the day side of the planet is transported, through the horizontal and vertical circulation, to the night side of the planet where it accumulates due to its long lifetime. As a result, the POC $\mathrm{TLE}(5-28)$ appears depleted on the day side and enhanced on the night side (Fig. 10g).

Due to the weak Coriolis force, large-scale meridional mixing takes place. The mean night side POC is $181 \mathrm{DU}$, and the mean day side POC is 158 DU (Fig. 10g). Therefore, in the lower stratosphere of the TLE, the day-night side variation is $\sim 13 \%$ with respect to the day side, which is two orders of magnitude higher compared to that of the PDE. The TLE tropospheric $\left[\mathrm{O}_{3}\right]$ is lower by two orders of magnitude compared to the stratosphere and, therefore, also does not contribute considerably to the $\mathrm{POC}_{\mathrm{TLE}(5-28)}$.

\section{Total ozone column}

Selsis (2000), Segura et al. (2005), Rugheimer et al. (2013), Rauer et al. (2011), Grenfell et al. (2007) and Kaltenegger et al. (2013) predicted that exoplanets orbiting F, G, $\mathrm{K}$ and $\mathrm{M}$ stars would produce a visible ozone spectral signature, with the strength of the signature varying depending on the star's UV radiation emission as well as the planet's molecular oxygen content. A planet's spectral ozone signature is derived from the planet's TOC, though the relation is not linear, as it also depends on the planet's temperature structure and distribution, its vertical ozone profile, the line of sight towards the observer, other atmospheric constituents and other factors.

The TOC $_{\text {TLE }}$ (Fig. 10h) is characterised by enhanced $\mathrm{O}_{3}$ columns on both the day and the night side and a well-mixed meridional TOC distribution (TOC $\mathrm{TLE}_{\mathrm{TE}}$ ). A comparison between Fig. 10f-h reveals that the main characteristics of the $\mathrm{TOC}_{\mathrm{TLE}}$ are formed in the lower and middle stratosphere.

Specifically, the enhanced features on the night side of the TLE originate in the lower stratosphere and are due to the transportation of ozone generated on the day side to the night side (Fig. 10h, g) through the horizontal and vertical circulation. The enhanced features of the TLE day side TOC are generated by the combined enhanced middle stratospheric POC (Fig. 10f) and the depleted day side lower stratospheric POC (Fig. 10g) and are, therefore, produced by a combination of photochemistry and dynamics. The depleted feature present on the left side of the globe (over the American continent) originates partly in the lower and partly in the middle stratosphere. In the lower stratosphere (Fig. 10g), the depletion appears as a result of the transport of the ozone depleted air present at the start of the simulation in the tropics, to their current location through the horizontal and vertical circulation. In the middle stratosphere (Fig. 10f), the depletion is the result of the lack of UV radiation on the night side of the planet combined with the downwelling of ozone poor air from the mesospheric day side (Fig. 10e).

The PDE and TLE TOC global means are presented in Table 3. The day and night side PDE and TLE hemisphere means are presented in Table 4. The TOC TLE global mean is $244.05 \mathrm{DU}$, while the TOC $\mathrm{PDE}$ global mean is 291.14 DU. The TOC $\mathrm{TLE}_{\mathrm{TL}}$ global mean is, therefore, reduced by $19.3 \%$ compared to the TOC $\mathrm{PDE}$ global mean. Therefore, the TLE $\mathrm{O}_{3}$ global concentration is depleted compared to the equivalent PDE, but not to the extent that would render the planet inhospitable to life. The day side $\mathrm{O}_{3}$

Table 3 Comparison of the TOC and POC global means obtained for the PDE simulation on day 1 and TLE simulation on day 90

\begin{tabular}{lcclc}
\hline & PDE (DU) & TLE (DU) & $\boldsymbol{\Delta}_{\%}(\%)$ & $\boldsymbol{\Delta}_{\text {DU }}(\mathrm{DU})$ \\
\hline TOC $_{G M}$ & 291.14 & 244.05 & 19.3 & 47.09 \\
POC $_{(5-28) G M}$ & 216.35 & 169.42 & 27.7 & 46.93 \\
POC $_{(30-45) G M}$ & 46.45 & 46.84 & -0.8 & -0.39 \\
POC $_{(55-110) G M}$ & 0.31 & 0.34 & -7.2 & -0.03 \\
\hline
\end{tabular}

The $\Delta_{\%}$ s are defined in Eqs. (1) and (2), while $\Delta_{\text {Dus }}$ are defined in Eqs. (3) and (4)

\begin{tabular}{|c|c|c|c|c|}
\hline & PDE day side & $\begin{array}{l}\text { PDE night } \\
\text { side }\end{array}$ & TLE day side & $\begin{array}{l}\text { TLE night } \\
\text { side }\end{array}$ \\
\hline & Mean (DU) & Mean (DU) & Mean (DU) & Mean (DU) \\
\hline $\mathrm{TOC}_{\mathrm{GM}}$ & 295 & 287 & 240 & 249 \\
\hline $\mathrm{POC}_{(5-28) \mathrm{GM}}$ & 220 & 213 & 158 & 181 \\
\hline $\mathrm{POC}_{(30-45) \mathrm{GM}}$ & 52 & 51 & 58 & 45 \\
\hline $\mathrm{POC}_{(55-110) \mathrm{GM}}$ & 0.23 & 0.40 & 0.28 & 0.40 \\
\hline
\end{tabular}


concentration of the TLE is also depleted compared to the daytime $\mathrm{O}_{3}$ concentration of the PDE, though it still remains within the limits of habitability.

The POC $\mathrm{TLE}(5-28)$ global mean is reduced by $27.7 \%$, while the POC $\operatorname{TLE}(30-45)$ global means is increased by $0.8 \%$, respectively, compared to the PDE. As mentioned before, due to the long lifetime of odd oxygen (and hence ozone) at these altitudes, the $\mathrm{POC}_{\mathrm{TLE}(5-28)}$ reduction can be attributed to the changed dynamics, which play a dominant role at these altitudes. The increased POC $_{\text {TLE(30-45), on the other hand, can be attributed }}$ equally to the influence of dynamics and photochemistry, due to the shortened lifetimes of odd oxygen at these altitudes. The POC $\mathrm{TLE}(55-110)$ global mean is increased by $7.2 \%$ compared to the PDE and at these altitudes can be attributed to the effects of photochemistry and transport of atomic oxygen. This increase has no major impact on the $\mathrm{TOC}_{\mathrm{TLE}}$ due to the small $\mathrm{POC}_{\mathrm{TLE}(55-110)}$ value $(<1 \mathrm{DU})$. As the bulk of the TOC $\mathrm{TLE}_{\mathrm{TL}}$ is provided by the stratosphere, the reduction in the TOC $\mathrm{TLE}$ can be attributed equally to the changed dynamics and photochemistry.

\section{Phases of the TLE}

As the planet moves around its parent star, different phases of the planet become visible to the observer (Fig. 11). The figure is an alteration of a figure by Winn (Seager et al. 2010). At any given time, only one side of the planet will be visible to the observers. It is, therefore, of interest to present the TOC hemisphere mean for different phases of the TLE and compare it with its PDE equivalent. We present the hemispheric TOC maps of the phases $\varphi=0^{\circ}, \varphi=90^{\circ}, \varphi=180^{\circ}$ and $\varphi=270^{\circ}$ of our simulated exoplanet. In phase $\varphi=0^{\circ}$, only the planet's day side is visible. In phases $\varphi=90^{\circ}$ and $\varphi=270^{\circ}$, half of the day side and half of the night side become visible.
In phase $\varphi=180^{\circ}$, only the night side is visible. Only the TOC values radially integrated from the surface to the top of the atmosphere are shown.

Figure 12a-d show these phases for the PDE. The phases are characterised by high ozone values at high latitudes. A long-distance observer would not notice a difference in the TOC maps of the PDE.

In contrast, the situation is different for the TLE. An observer would notice TOC depletion or enhancement depending on the observed hemisphere. This can be seen in Fig. 12e-h which present the TOC ${ }_{\text {TLE }}$ of the subsolar hemisphere $\left(\operatorname{TOC}_{\operatorname{TLE}\left(0^{\circ}\right)}\right)$, the dusk hemisphere

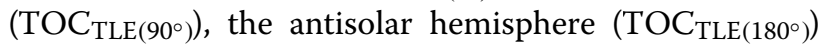
and the dawn hemisphere $\left(\operatorname{TOC}_{\operatorname{TLE}\left(270^{\circ}\right)}\right)$, respectively.

Table 5 shows the changes in the hemisphere means of the $\triangle T O C_{(T L E, T L E)}$ compared to the $\operatorname{TOC}_{\mathrm{TLE}\left(0^{\circ}\right) \text {. It is clear that }}$ the $\mathrm{TOC}_{\mathrm{TLE}\left(90^{\circ}\right)}$ is depleted compared to the $\mathrm{TOC}_{\mathrm{TLE}\left(270^{\circ}\right) \text {. }}$ It is characterised by low $\mathrm{O}_{3}$ columns, with the depleted region coinciding with the TLE dusk region (Fig. 12f).

The $\mathrm{TOC}_{\operatorname{TLE}\left(180^{\circ}\right)}$ (Fig. 12g) is enhanced compared to the $\operatorname{TOC}_{\operatorname{TLE}\left(0^{\circ}\right)}$ (Fig. 12e) and is characterised by high $\mathrm{O}_{3}$ concentrations between the antisolar point (depicted with a white point) and the subsolar point (depicted with a black point) and low concentrations towards the North-West part of the hemisphere.

A comparison between the TOC $\mathrm{PDE}$ and $\mathrm{TOC}_{\mathrm{TLE}}$ values in Table 6 reveals that the TOC $\mathrm{TLE}$ is depleted compared to the TOC $\mathrm{PDE}$ irrespective of the observed hemisphere.

It is, therefore, clear that the $\mathrm{TOC}_{\mathrm{TLE}}$ distribution will differ depending on the side of the planet observed. The difference in the four phases between the PDE and the TLE is on average $\triangle T O C \sim 20 \%$. Depending on the temperature structure of the atmosphere, the vertical ozone profile and other factors, the change in the observed spectral line can be at most $10 \%$. Since the measurement

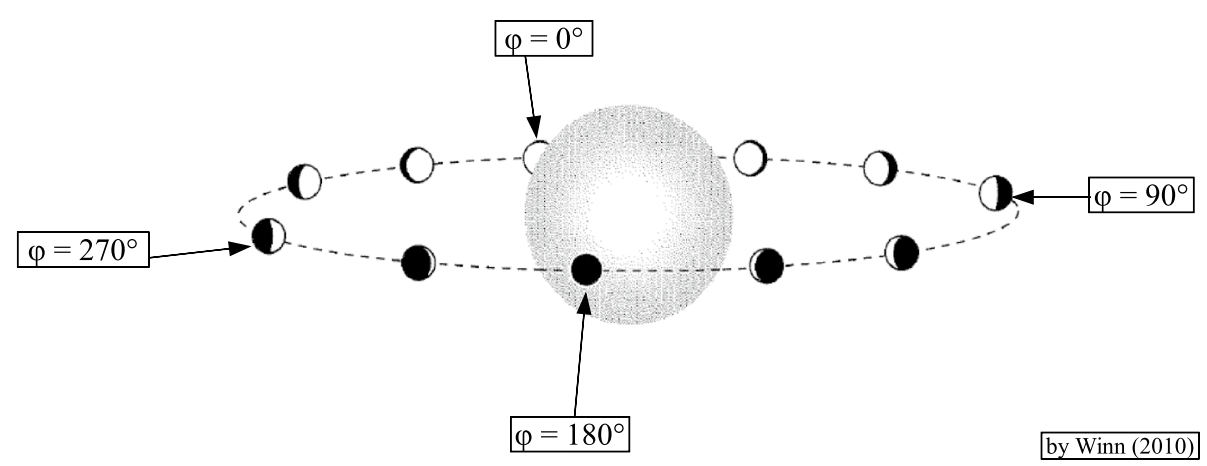

Fig. 11 Phases of an exoplanet as seen by an observer. The phases $\varphi=0^{\circ}, \varphi=90^{\circ}, \varphi=180^{\circ}$ and $\varphi=270^{\circ}$ have been marked. In phase $\varphi=0^{\circ}$, only the planet's day side is visible. In phases $\varphi=90^{\circ}$ and $\varphi=270^{\circ}$, half of the day side and half of the night side are visible. In phase $\varphi=180^{\circ}$, only the night side is visible 


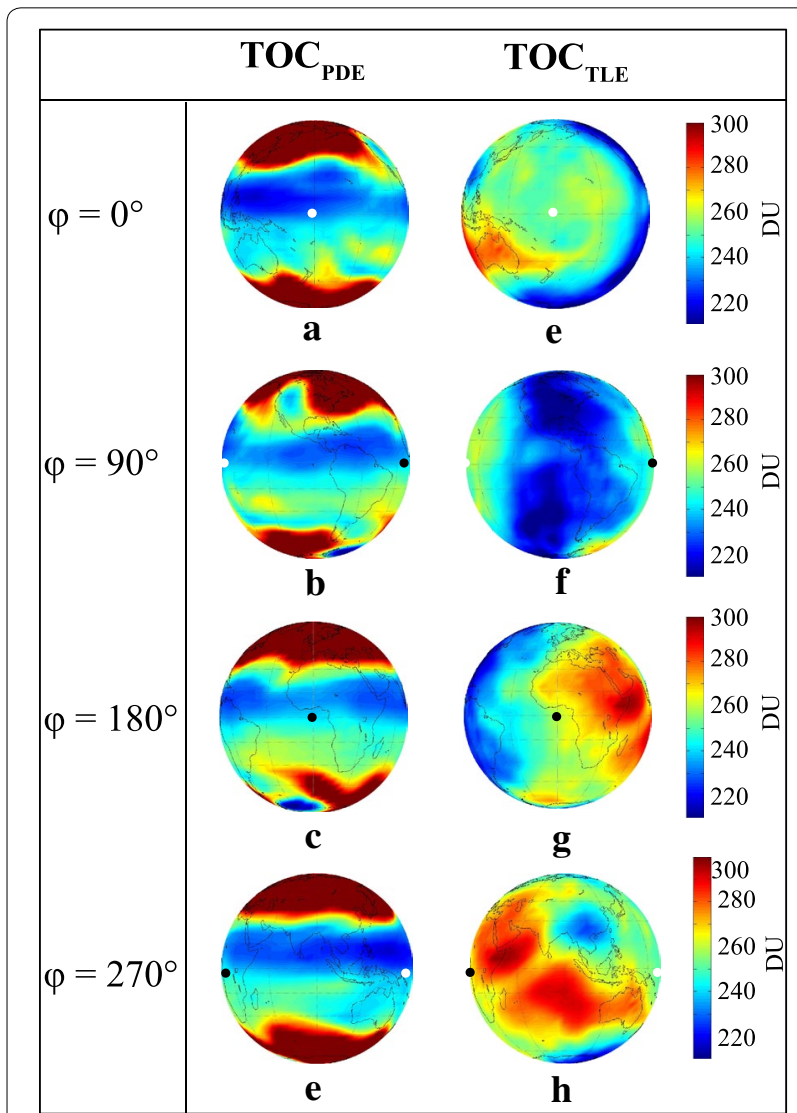

Fig. 12 Comparative view of four different phases of the TOC $P D E$ and TOC TLE. $\mathbf{a} \varphi=0^{\circ}$ of TOC $P D E, \quad \mathbf{b} \varphi=90^{\circ}$ of TOCPDE, $\mathbf{c} \varphi=180^{\circ}$ of

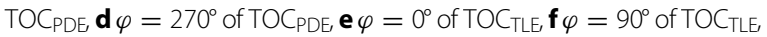
$\mathbf{g} \varphi=180^{\circ}$ of TOC TLE and $\mathbf{h} \varphi=270^{\circ}$ of TOC TLE. The antisolar point is indicated with a white point. The subsolar point is indicated with a blackpoint

errors of the observed exoplanet spectra currently range between 10 and $30 \%$ (Burrows 2014), the difference will not be critical for observations at present. However, as bigger telescopes and improved observing and data analysis techniques are developed, differences in the hemispheric TOC of tidally locked exoplanets might become detectable.

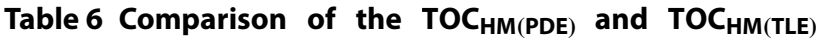
hemisphere means for different phases of the planet

\begin{tabular}{lll}
\hline Phase $\boldsymbol{\varphi}$ & TOC $_{\text {PDE }}$ (DU) & TOC $_{\text {TLE }}$ (DU) \\
\hline $0^{\circ}$ & 295 & 239 \\
$90^{\circ}$ & 285 & 234 \\
$180^{\circ}$ & 287 & 249 \\
$270^{\circ}$ & 291 & 260 \\
\hline
\end{tabular}

\section{Conclusions}

We discussed and compared the 3D ozone distributions of the present-day Earth (PDE) and a tidally locked Earthlike exoplanet revolving around a Sun-like star (TLE). We demonstrated that it is possible to simulate the middle atmosphere of a TLE using the realistic, high-resolution, 3D chemistry-climate model (CESM1(WACCM)). We further demonstrated that the simulation achieves a steady state for the middle atmosphere within 80 days.

A comparison between the middle atmospheres of the PDE and TLE reveals that the ozone distribution of the TLE is greatly altered due to the reduced Coriolis force and the breakdown of the Brewer-Dobson circulation. The TLE simulation shows an upwelling centred over the day side and a downwelling centred over the night side. The primary ozone layer is enhanced on the day side and depleted on the night side compared to its PDE equivalent. The secondary ozone layer is enhanced on the night side, while the day side remains relatively unchanged and the tertiary ozone layer disappears.

We studied the TOC of four phases of the planet, with respect to a remote observer. The TOC means of the four phases of the TLE are reduced by $\sim 19.8 \%$ compared to the PDE.

The observations conducted with our existing telescopes have a $30 \%$ error margin, which is approximately 1.5 times higher than the $\approx 20 \%$ TOC change. Therefore, even though the TOC of the TLE greatly differs from that of the PDE, it is not possible, with our current technology, to detect the difference and the observations will, therefore, not be affected.

Table 5 Comparison of the difference between the $\mathrm{TOC}_{H M(P D E)}$ and $\mathrm{TOC}_{H M(T L E)}$ hemisphere means for different phases of the planet

\begin{tabular}{|c|c|c|c|c|}
\hline Phase $\varphi$ & $\Delta \mathrm{TOC}_{\mathrm{HM}(\mathrm{PDE}, \mathrm{TLE})}(\mathrm{DU})$ & $\Delta T^{T O C} C_{H M(P D E, T L E)}(\%)$ & $\Delta \mathrm{TOC}_{\mathrm{HM}(\mathrm{TLE}, \mathrm{TLE})}(\%)$ & $\begin{array}{l}\left.\Delta T^{\Delta O C_{H M}(P D E, P D E}\right) \\
(\%)\end{array}$ \\
\hline $0^{\circ}$ & -56 & 23 & 0 & 0 \\
\hline $90^{\circ}$ & -51 & 22 & 2.2 & 3.5 \\
\hline $180^{\circ}$ & -39 & 16 & -3.8 & 2.7 \\
\hline $270^{\circ}$ & -13 & 12 & -8.1 & 1.4 \\
\hline
\end{tabular}


The atmospheric phenomena discussed in this paper are generated as a result of the interplay between photochemistry and dynamics, making the study of the middle atmosphere of Earth-like planets a new branch of research.

In the present study, we focused on the ozone distribution of an Earth-like tidally locked planet, only briefly mentioning the planet's atmospheric circulation. However, the variable jet streams and large-scale vortices in the middle atmosphere of the TLE are astonishing. More investigations with advanced data analysis techniques are required to describe the $3 \mathrm{D}$ circulation of the TLE. A 3D study of a tidally locked Earth-like planet orbiting an $M$ dwarf star, where both the different stellar spectrum and the tidal lock are included in the model, is also a possible future project.

When only atmospheric chemistry is considered, as in the case of Segura et al. (2005), the total ozone column of an Earth-like planet is determined by the UV radiation of the stellar spectrum used. The use of a flaring $M$ star spectrum, whose UV radiation output in the $200 \mathrm{~nm}$ region is comparable to the Sun's, results in no decrease and even an increase in the total ozone column. The use of a quiescent $M$ star spectrum, on the other hand, whose UV output in the $200 \mathrm{~nm}$ region is more than three order of magnitude lower than the Sun's, results in a decrease in the total ozone column by $40 \%$.

When dynamics but no photochemistry or atmospheric chemistry is considered, as in the case of the $3 \mathrm{D}$ Godolt et al. (2015) study, the stratospheric temperature of an Earth-like planet is also determined by the UV radiation of the stellar spectrum used. Higher UV radiation (e.g. an F star spectrum) results in increased stratospheric temperatures, while lower UV radiation (e.g. a K star spectrum) leads to decreased stratospheric temperatures. Had the simulations included photochemistry and atmospheric chemistry, their outcomes would possibly show a different behaviour than described above.

The ozone generation and destruction rates depend on the ambient temperature, the abundance of atomic and molecular oxygen and the photodissociation of the ozone molecules by the stellar UV radiation. Therefore, the final total ozone column will depend on the balance reached between these three processes, whose prediction is not trivial.

It is possible that a combination of tidal locking and a change to an "M dwarf spectrum" will probably lead to a decrease in the planet's total ozone column, compared to a spectrum change-only simulation.

\section{Abbreviations}

ATM: atmosphere model; CESM: Community Earth System Model; CICE: sea-ice data model; CLM: Community Land Model; CPL: Coupler to CESM;
GLC: land-ice geophysical model in CESM; ICE: sea-ice geophysical model in CESM; docn: prescribed data ocean model; LND: land geophysical model in CESM; MODIS: moderate-resolution imaging spectroradiometer; OCN: ocean geophysical model in CESM; WACCM: Whole Atmosphere Community Climate Model; NOAA: National Oceanic and Atmospheric Administration; PDE: present-day Earth; TLE: tidally locked Earth; TOC: total ozone column; POC: partial ozone column; TOCPDE: TOC of the PDE; TOC TLE: TOC of the TLE; POCPDE : POC of the PDE; POC TLE: POC of the TLE; POCPDE(5-28): $P_{(5-28)}$ of the PDE;

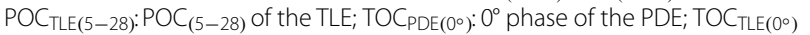
$: 0^{\circ}$ phase of the TLE.

\section{Authors' contributions}

EP performed the simulations, data analysis and interpretation. $\mathrm{KH}$ contributed to the data analysis and interpretation. Both authors read and approved the final manuscript.

\section{Author details}

${ }^{1}$ Institute of Applied Physics, University of Bern, Sidlerstrasse 5, 3012 Bern, Switzerland. ${ }^{2}$ Center for Space and Habitability, University of Bern, Sidlerstrasse 5, 3012 Bern, Switzerland. ${ }^{3}$ Oeschger Centre for Climate Change Research, University of Bern, Falkenplatz 16, 3012 Bern, Switzerland.

\section{Acknowledgements}

We would like to thank the Center for Space and Habitability (University of Bern) for the PhD fellowship that made this study possible. We would like to thank the WACCM forum for the invaluable information it provided. We would also like to thank Ansgar Schanz and Martin Lainer for the computer technical support they provided. Finally we would like to thank Niklaus Kämpfer, Peter Wurz and Helmut Lammer for the valuable discussions and advises.

\section{Competing interests}

The authors declare that they have no competing interests.

Received: 6 March 2015 Accepted: 6 May 2016

Published online: 01 June 2016

\section{References}

Ackerman M (1971) Ultraviolet solar radiation related to mesospheric processes. In: Fiocco G (ed) Mesospheric models and related experiments: proceedings of the fourth esrin-eslab symposium held in Frascati, Italy, 6-10 July, 1970. Springer, Netherlands, pp 149-159

Andrews G (2010) David an introduction to atmospheric physics, 2nd edn. Cambridge University Press, Cambridge

Bönisch H, Engel A, Birner T, Hoor P, Tarasick DW, Ray EA (2011) On the structural changes in the Brewer-Dobson circulation after 2000. Atmos Chem Phys 11:3937-3948. doi:10.5194/acp-11-3937-2011

Brasseur PG, Solomon S (2005) Aeronomy of the middle atmosphere, chemistry and physics of the stratosphere and mesosphere, chemistry and physics of the stratosphere and mesosphere, 3rd edn. Springer, Dordrecht

Burrows AS (2014) Spectra as windows into exoplanet atmospheres. Proc Natl Acad Sci USA 111:12601-12609. doi:10.1073/pnas.1304208111

Callies J, Corpaccioli E, Eisinger M, Lefebvre A, Munro R, Perez-Albinana A, Ricciarelli B, Calamai L, Gironi G, Veratti R, Otter G, Eschen M, van Riel L (2004) GOME-2 ozone instrument onboard the European METOP satellites. Proc SPIE 5549:60-70. doi:10.1117/12.557860

Clough SA, Shephard MW, Mlawer EH, Delamere JS, lacono MJ, Cady-Pereira K, Boukabara S, Brown PD (2005) Atmospheric radiative transfer modeling: a summary of the AER codes. J Quant Spectrosc Radiat Transf 91:233-244. doi:10.1016/j.jqsrt.2004.05.058

Clough S, lacono M (1995) Line-by-line calculation of atmospheric fluxes and cooling rates 2 . Application to carbon dioxide, ozone, methane, nitrous oxide and the halocarbons. J Geophys Res 100:16519-16535. doi:10.1029/95JD01386

Davis RN, Du J, Smith AK, Ward WE, Mitchell NJ (2013) The diurnal and semidiurnal tides over ascension island $\left({ }^{\circ} \mathrm{s}, 14^{\circ} \mathrm{W}\right)$ and their interaction with the stratospheric quasi-biennial oscillation: studies with meteor radar, eCMAM and WACCM. Atmos Chem Phys 13:9543-9564. doi:10.5194/ acp-13-9543-2013 
Edson A, Lee S, Bannon P, Kasting JF, Pollard D (2011) Atmospheric circulations of terrestrial planets orbiting low-mass stars. Icarus 212:1-13. doi:10.1016/j.icarus.2010.11.023

Godolt M, Grenfell JL, Hamann-Reinus A, Kitzmann D, Kunze M, Langematz U, von Paris P, Patzer ABC, Rauer H, Stracke B (2015) 3D climate modeling of Earth-like extrasolar planets orbiting different types of host stars. Planet Space Sci 111:62-76. doi:10.1016/j.pss.2015.03.01

Grenfell JL, Stracke B, von Paris P, Patzer B, Titz R, Segura A, Rauer H (2007) The response of atmospheric chemistry on earthlike planets around $F, G$ and K Stars to small variations in orbital distance. Planet Space Sci 55:661-671. doi:10.1016/j.pss.2006.09.00

Grenfell JL, Gebauer S, Godolt M, Palczynski K, Rauer H, Stock J, von Paris P, Lehmann R, Selsis F (2013) Potential biosignatures in super-Earth atmospheres II. Photochemical responses. Astrobiology 13:415-438. doi:10.1089/ast.2012.0926

Grenfell JL, Gebauer S, Paris PV, Godolt M, Rauer H (2014) Sensitivity of biosignatures on Earth-like planets orbiting in the habitable zone of cool M-dwarf Stars to varying stellar UV radiation and surface biomass emissions. Planet Space Sci 98:66-76. doi:10.1016/j.pss.2013.10.00

Haberle RM, McKay CP, Tyler D, Reynolds RT, Doyle LR (1996) Can synchronously rotating planets support an atmosphere? In: Doyle LR (ed) Proceedings of the first international conference on circumstellar habitable zones, Menlo Park, CA, p 29. Travis House Publications

lacono M, Delamere J, Mlawer ME, Shephard, Clough S, Collins W (2008) Radiative forcing by long-lived greenhouse gases: calculations with the AER radiative transfer models. J Geophys Res Atmos 113. doi:10.1029/20 08JD009944

Joshi MM, Haberle RM, Reynolds RT (1997) Simulations of the atmospheres of synchronously rotating terrestrial planets orbiting $\mathrm{m}$ dwarfs: conditions for atmospheric collapse and the implications for habitability. Icarus 129:450-465

Joshi M (2003) Climate model studies of synchronously rotating planets. Astrobiology 3:415-427. doi:10.1089/153110703769016488

Kaltenegger L, Sasselov D, Rugheimer S (2013) Water-planets in the habitable zone: atmospheric chemistry, observable features, and the case of Kepler62e and -62f. Astrophys J Lett 775:47. doi:10.1088/2041-8205/775/2/L47

Kaspi Y, Showman AP (2015) Atmospheric dynamics of terrestrial exoplanets over a wide range of orbital and atmospheric parameters. Astrophys J 804:60. doi:10.1088/0004-637X/804/1/60

Kasting JF, Donahue TM (1980) The evolution of atmospheric ozone. J Geophys Res 85:3255-3263. doi:10.1029/JC085iC06p03255

Kaufmann M, Gusev OA, Grossmann KU, Martín-Torres FJ, Marsh DR, Kutepov AA (2003) Satellite observations of daytime and nighttime ozone in the mesosphere and lower thermosphere. J Geophys Res 108(D9):4272. doi:10.1029/2002JD002800

Lean J (2000) Evolution of the sun's spectral irradiance since the maunder minimum. Geophys Res Lett 27(16):2425-2428. doi:10.1029/2000GL000043

Liu X, Chance K, Sioris CE, Kurosu TP (2007) Impact of using different ozone cross sections on ozone profile retrievals from global ozone monitoring experiment (gome) ultraviolet measurements. Atmos Chem Phys 7(13):3571-3578. doi:10.5194/acp-7-3571-2007

Lu X, Liu H-L, Liu AZ, Yue J, McInerney JM, Li Z (2012) Momentum budget of the migrating diurnal tide in the whole atmosphere community climate model at vernal equinox. J Geophys Res Atmos 17:07112. doi:10.1002/20 13JA019421

Marsh D, Smith A, Brasseur G, Kaufmann M, Grossmann K (2001) The existence of a tertiary ozone maximum in the high-latitude middle mesosphere. Geophys Res Lett 28:4531-4534. doi:10.1029/2001GL013791

Marsh DR, Skinner WR, Marshall AR, Hays PB, Ortland DA, Yee J-H (2002) High resolution Doppler imager observations of ozone in the mesosphere and lower thermosphere. J Geophys Res 107(D19):4390. doi:10.1029/20 01JD001505

Menou K (2013) Water-trapped Worlds. Astrophys J 774:51. doi:10.1088/0004-637X/774/1/51

Merlis TM, Schneider T (2010) Atmospheric dynamics of earth-like tidally locked aquaplanets. J Adv Model Earth Syst 2:13. doi:10.3894/ JAMES.2010.2.13

Mlawer E, Taubman S, Brown P, lacono M, Clough S (1997) Radiative transfer for inhomogeneous atmospheres: RRTM, a validated correlated-k model for the longwave. J Geophys Res 102:16663-16682. doi:10.1029/97JD00237
Montmessin F, Bertaux JL, Lefevre F, Marcq E, Belyaev D, Gerard JC, Korablev O, Fedorova A, Sarago V, Vandaele AC (2011) A layer of ozone detected in the nightside upper atmosphere of Venus. Icarus 216:82-85. doi:10.1016/j.icarus.2011.08.010

Müller R (2012) Stratospheric ozone depletion and climate change. The Royal Society of Chemistry, Thomas Graham House, Cambridge

National Oceanic and Atmospheric Administration, U.s.A.F. National Aeronautics and Space Administration (1976) U.S. Standard Atmosphere, U.S. Government Printing Office, Washington, DC

Neale RB, Gettelman A, Park S, Chen C, Lauritzen PH, Williamson DK, Conley AJ, Kinnison D, Marsh D, Smith AK, Vitt F, Garcia R, Lamarque JF, Mills M, Tilmes S, Morrison H, Cameron-Smith W, Collins WD, lacono MT, Easter RC, Liu X, Ghan SJ, Rasch PJ, Taylor MA (2012) Description of the NCAR community atmosphere model (CAM 5.0). http://www.cesm.ucar.edu/ models/cesm1.0/cam/docs/description/cam5_desc.pdf

Ozone Atmosphere (1985) WMO global ozone research and monitoring project, Report

Pedatella NM, Fuller-Rowell T, Wang H, Jin H, Miyoshi Y, Fujiwara H, Shinagawa H, Liu H-L, Sassi F, Schmidt H, Matthias V, Goncharenko L (2014) The neutral dynamics during the 2009 sudden stratosphere warming simulated by different whole atmosphere models. J Geophys Res Space Phys 119:1306-1324. doi:10.1002/2013JA019421

Pedatella NM, Liu H-L (2013) Influence of the El Niño Southern Oscillation on the middle and upper atmosphere. J Geophys Res Space Phys 118:2744-2755. doi:10.1002/jgra.50286

Rauer H, Gebauer S, Paris Pv, Cabrera J, Godolt M, Grenfell JL, Belu A, Selsis F, Hedelt P, Schreier F (2011) Potential biosignatures in super-Earth atmospheres I. Spectral appearance of super-Earths around M dwarfs. Astron Astrophys 529:8. doi:10.1051/0004-6361/20101436

Rugheimer S, Kaltenegger L, Zsom A, Segura A, Sasselov D (2013) Spectral fingerprints of Earth-like planets around FGK stars. Astrobiology 13(3):251269. doi:10.1089/ast.2012.0888

Sakazaki T, Fujiwara M, Mitsuda C, Imai K, Manago N, Naito Y, Nakamura T, Akiyoshi H, Kinnison D, Sano T, Suzuki M, Shiotani M (2013) Diurnal ozone variations in the stratosphere revealed in observations from the Superconducting Submillimeter-Wave Limb-Emission Sounder (SMILES) on board the International Space Station (ISS). J Geophys Res Atmos 118:2991-3006. doi:10.1002/jgrd.50220

Sander SP, Friedl RR, Golden DM, Kurylo MJ, Moortgat GK, Wine PH, Ravishankara AR, Kolb CE, Molina MJ, Finlayson-Pitts BJ, Huie RE (2006) Chemical kinetics and photochemical data for use in atmospheric studies. Evaluation number 15. National Aeronautics and Space Administration, Jet Propulsion Laboratory, Pasadena, CA

Seager S, Dotson RŽ, Institute LP (2010) Exoplanets. University of Arizona Press, Main Library Building, 5th Floor, 1510 E. University Blvd., P.O. Box 210055, Tucson, AZ 85721-0055

Segura A, Krelove K, Kasting JF, Sommerlatt D, Meadows V, Crisp D, Cohen M, Mlawer E (2003) Ozone concentrations and ultraviolet fluxes on Earth-like planets around other stars. Astrobiology 3:689-708. doi:10.1089/15311070332273602

Segura A, Kasting JF, Meadows V, Cohen M, Scalo J, Crisp D, Butler RAH, Tinetti G (2005) Biosignatures from Earth-like planets around M-dwarfs. Astrobiology 5:706-725. doi:10.1089/ast.2005.5.70

Segura A, Walkowicz LM, Meadows V, Kasting J, Hawley S (2010) The effect of a strong stellar flare on the atmospheric chemistry of an Earth-like planet orbiting an M dwarf. Astrobiology 10:751-776. doi:10.1089/ast.2009.037

Selsis F (2000) Review: physics of planets I Darwin and the atmospheres of terrestrial planets. In: Schü"rmann B (ed) Darwin and astronomy the infrared space interferometer, vol 451. esa special publication, Noordwijk, p 133

Smith KL, Polvani LM, Marsh DR (2012) Mitigation of 21st century Antarctic sea ice loss by stratospheric ozone recovery. Geophys Res Lett 39:20701. doi: 10.1029/2012GL053325

Solomon S, Qiang L (2005) Solar extreme-ultraviolet irradiance for general circulation models. J Geophys Res 110:10306. doi:10.1029/2005JA011160

Tan B, Chu X, Liu H-L, Yamashita C, Russell JM (2012) Atmospheric semidiurnal lunar tide climatology simulated by the whole atmosphere community climate model. J Geophys Res 117:06327. doi:10.1029/2012JA017792

Tan B, Chu X, Liu H-L, Yamashita C, Russell JM (2012) Zonal-mean global teleconnection from 15 to $110 \mathrm{~km}$ derived from SABER and waccm. J Geophys Res Atmos 117:10106. doi:10.1029/2011JD016750 
Tan B, Chu X, Liu H-L, Yamashita C, Russell JM (2012) Parameterization of the inertial gravity waves and generation of the quasi-biennial oscillation. J Geophys Res Atmos 117:06103. doi:10.1029/2011JD016778

Tanaka Y, Inn ECY, Watanabe K (1953) Absorption coefficients of gases in the vacuum ultraviolet. Part IV. Ozone. J Chem Phys 21(10):1651-1653. doi:10.1063/1.1698638

Tarter JC, Backus PR, Mancinelli RL, Aurnou JM, Backman DE, Basri GS, Boss AP, Clarke A, Deming D, Doyle LR, Feigelson ED, Freund F, Grinspoon DH, Haberle RM, Hauck SAI, Heath MJ, Henry TJ, Hollingsworth JL, Joshi MM, Kilston S, Liu MC, Meikle E, Reid IN, Rothschild LJ, Scalo J, Segura A, Tang CM, Tiedje JM, Turnbull MC, Walkowicz LM, Weber AL, Young RE (2007) A reappraisal of the habitability of planets around $\mathrm{M}$ dwarf stars. Astrobiology 7:30-65. doi:10.1089/ast.2006.0124

Veefkind JP, de Haan JF, Brinksma EJ, Kroon M, Levelt PF (2006) Total ozone from the ozone monitoring instrument (omi) using the doas technique. IEEE Geosci Remote Sensing Soc 44:1239-1244. doi:10.1109/ TGRS.2006.871204
Vertenstein M, Craig T, Middleton A, Feddema D, Fisher C (2012) CESM 1.0.4 user's guide. http://www.cesm.ucar.edu/models/cesm1.0/cesm/cesm_ doc_1_0_4/book1.html

Wallas JM, Hobbs PV (2006) Atmospheric science an introductory survey, 2nd edn. Academic Press, San Diego

Wang Y-M, Lean JL, Sheeley NRJ (2005) Modeling the sun's magnetic field and irradiance since 1713. Astrophys J 625(1):522

Yang J, Cowan NB, Abbot DS (2013) Stabilizing cloud feedback dramatically expands the habitable zone of tidally locked planets. Astrophys J Lett 771:45. doi:10.1088/2041-8205/771/2/L45

Yang J, Boué G, Fabrycky DC, Abbot DS (2014) Strong dependence of the inner edge of the habitable zone on planetary rotation rate. Astrophys J Lett 787:2. doi:10.1088/2041-8205/787/1/L2

\section{Submit your manuscript to a SpringerOpen ${ }^{\odot}$ journal and benefit from:}

- Convenient online submission

- Rigorous peer review

- Immediate publication on acceptance

- Open access: articles freely available online

- High visibility within the field

- Retaining the copyright to your article 